\title{
Characteristic Seismic Waves Associated with Cryosphere Dynamics in Eastern Dronning Maud Land, East Antarctica
}

\author{
Masaki Kanao,, ${ }^{1}$ Akira Yamada, ${ }^{2}$ and Mikiya Yamashita ${ }^{3}$ \\ ${ }^{1}$ National Institute of Polar Research, Research Organization of Information and Systems, 10-3 Midori-cho, Tachikawa-shi, \\ Tokyo 190-8518, Japan \\ ${ }^{2}$ Geodynamics Research Center, Ehime University, Bunkyo-cho 2-5, Matsuyama, Ehime 790-8577, Japan \\ ${ }^{3}$ Institute for Research on Earth Evolution, Japan Agency for Marine-Earth Science and Technology, Showa-machi 3175-25, \\ Kanazawa-ku, Yokohama 236-0001, Japan
}

Correspondence should be addressed to Masaki Kanao, kanao@nipr.ac.jp

Received 6 March 2012; Revised 7 July 2012; Accepted 10 August 2012

Academic Editor: Michael S. Zhdanov

Copyright (C) 2012 Masaki Kanao et al. This is an open access article distributed under the Creative Commons Attribution License, which permits unrestricted use, distribution, and reproduction in any medium, provided the original work is properly cited.

\begin{abstract}
Several kinds of natural source signals are recorded by seismic exploration stations on the continental ice sheet in Eastern Dronning Maud Land, East Antarctica, during 2002 austral summer. They include not only tectonic earthquakes, but also icerelated phenomena possibly involving recent global climate change. The recorded signals are classified into (1) teleseismic events, (2) local ice quakes, and (3) unidentified events (X-phases). The teleseismic waves show the high signal-to-noise ratio in spite of the small magnitude of the event; this indicates that it is highly feasible to study not only the local shallow structure but also the deep structure of the earth by using teleseismic events. Frequency spectra of the all waveforms represent discordances along the observation seismic profile. The abrupt change of topography in the valley along the seismic profile might cause both the anomalous frequency content and travel times. Finally, an origin of the X-phases is speculated as the intraplate earthquakes or possibly large ice-quakes (glacial earthquakes) around Antarctica, involving global warming appeared in polar region.
\end{abstract}

\section{Introduction}

It was generally understood by a majority of seismologists in the IGY era that no extreme earthquakes occurred in the Antarctic. Though the Antarctic was known as an aseismic region, some significant earthquakes have occurred both on the Antarctic continent and in the surrounding oceans. Although the seismic stations in Antarctica have been operated as a part of global network, no detailed studies of local events have been made until recently $[1,2]$. The density of station distribution of both permanent stations belonging to the global network, as well as the temporary deployed stations at specified regions, has improved over time, and has recently permitted several studies of seismicity in the Antarctic [3-5].

Several kinds of signals associated with environmental changes in the atmosphere-ocean-solid earth system have been detected in Antarctica and the surroundings. Ice-related seismic motions for small-magnitude events are generally named "ice quakes" (or "ice shocks" for smaller events) and can be generated by glacially related dynamics [68]. Such cryoseismic sources include the movements of ice sheets, sea ice, oceanic tide cracks, oceanic gravity waves, icebergs and the calving fronts of ice caps. Sometimes, we can hardly distinguish between the waveforms generated by local tectonic earthquakes and those of ice-related phenomena; however, the cryoseismic sources are likely to be influenced by surface environmental conditions, and the study of their temporal variation may provide indirect evidence of climate change.

Temporary deep seismic exploration was performed by the Japanese Antarctic Research Expedition (JARE) on the Mizuho Plateau, Eastern Dronning Maud Land, East Antarctica, during the 2002 austral summer. The exploration was conducted as a part of the project on "Structure and Evolution of the East Antarctic Lithosphere (SEAL)" $[9,10]$ in order to reveal the structure of the crust and upper mantle beneath the investigated region (Figure 1). 


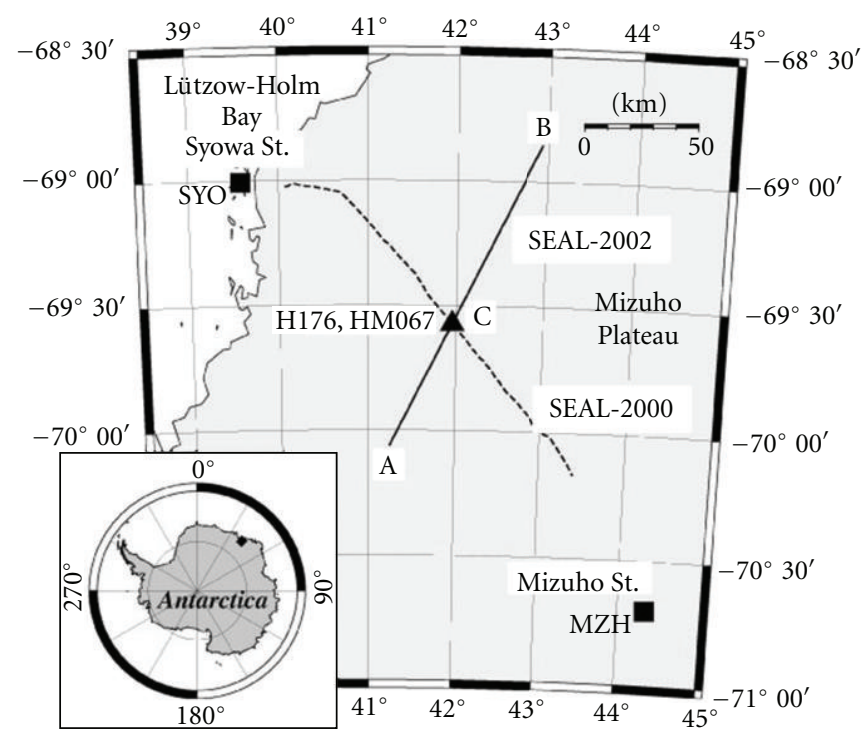

Figure 1: Location map of the seismic profile for SEAL-2002 exploration (solid line; between A and B), together with SEAL-2000 profile (broken line) on the Mizuho Plateau, Eastern Dronning Maud Land, East Antarctica. The data retrieved by SEAL-2002 exploration were used in this study. Names of nearby Japanese stations are as follows: Syowa St. (SYO) at the coast of Lützow-Holm Bay and Mizuho St. (MZH) on ice-sheet plateau. The intersection station of the two seismic profiles (C) is indicated by a solid triangle (H176 and HM067 are station codes for SEAL-2000 and SEAL-2002, resp.). The distance measured from the southwestern terminal (A) along the SEAL-2002 profile is utilized as the abscissa in several record sections in this paper (Figures 3, 4, 6, 7, 9, 10, 11, 12, 13, 14, and 15). The extended area in Antarctic continent is indicated by solid rectangle as shown at the lower left.

The SEAL-2002 experiment recorded chiefly the artificial waveforms originated by seven large explosions with 161 temporary stations along the transect profile, which is almost parallel with the coast of the Lützow-Holm Bay [11]. They determined the P-wave velocity structure of the crust and upper mantle as well as the overlying ice sheet by seismic travel time analysis.

An interesting feature of the obtained structure presents a complex topography of the boundary between ice sheet and crystalline crust. Several geophysical data measured along the SEAL-2002 profile are compiled in Figure 2. Elevation of icesheet surface, free-air gravity anomaly, depths of the bedrock inferred from radioecho soundings [13], together with the bedrock from seismic travel time analysis [11], is shown in the same figure. The bedrock topography is attributed by a remarkable valley structure having about $10 \mathrm{~km}$ width beneath the middle part of the seismic profile. The P-wave velocities beneath this valley area are estimated to be slower $(5.9-6.0 \mathrm{~km} / \mathrm{s})$ than those of the other area in the profile $(6.1-6.2 \mathrm{~km} / \mathrm{s})$.

In addition to the bedrock topography, detailed information of reflection images from radioecho sounding within the ice sheet, as well as strong reflections from bedrock surface, is represented in upper of Figure 2 (modified after [13]). It is noticed that there are specific areas in the profile without any reflections from the bedrock (around C, and the area between the stations of L139 and L154). A plausible possibility of low P-wave velocity appeared in the valley is explained by the presence of water infilling the area [14], which also produces less reflections by radioecho sounding. These phenomena are reported as the existence of a significant number of subglacial lakes in wide area of inland Antarctic continent [15, 16].

In addition to artificial seismic sources by deep explosion exploration, several kinds of characteristic waves associated with natural environmental variations are clearly recorded in the SEAL-2002 data. In spite of the recording time lengths limited to only several minutes in a day during the one month of the experiment, a total of sixteen time windows clearly identified the contamination of characteristic natural source events (regional and teleseismic events, local events including ice quakes, and unknown phases; Table 1).

In this paper, remarkable features of the anomalies in the travel-times, amplitudes, and frequency contents are demonstrated in several examples of the recorded waveforms from natural sources recorded by the SEAL-2002 data. In discussion, particularly, the origin of unknown characteristic phases is treated by focusing on the relationship with recent dynamics of ice-related phenomena (including glacial earthquakes), climate changes appearing in polar region, as well as the hidden (uninvestigated) microseismic activities around the Antarctic.

\section{Data and Analysis}

A total of 161 seismic stations by vertical component with a natural period of $0.5 \mathrm{~s}$ are aligned in the SEAL2002 exploration profile (Figure 1) with an interval of approximately $1 \mathrm{~km}(0.5 \mathrm{~km}$ interval for a $10 \mathrm{~km}$ span in the middle part of the line). Digital recordings with duration of seven and half minutes were performed twice a day (14:00 and 16:00 in UTC) during the experiments from January 


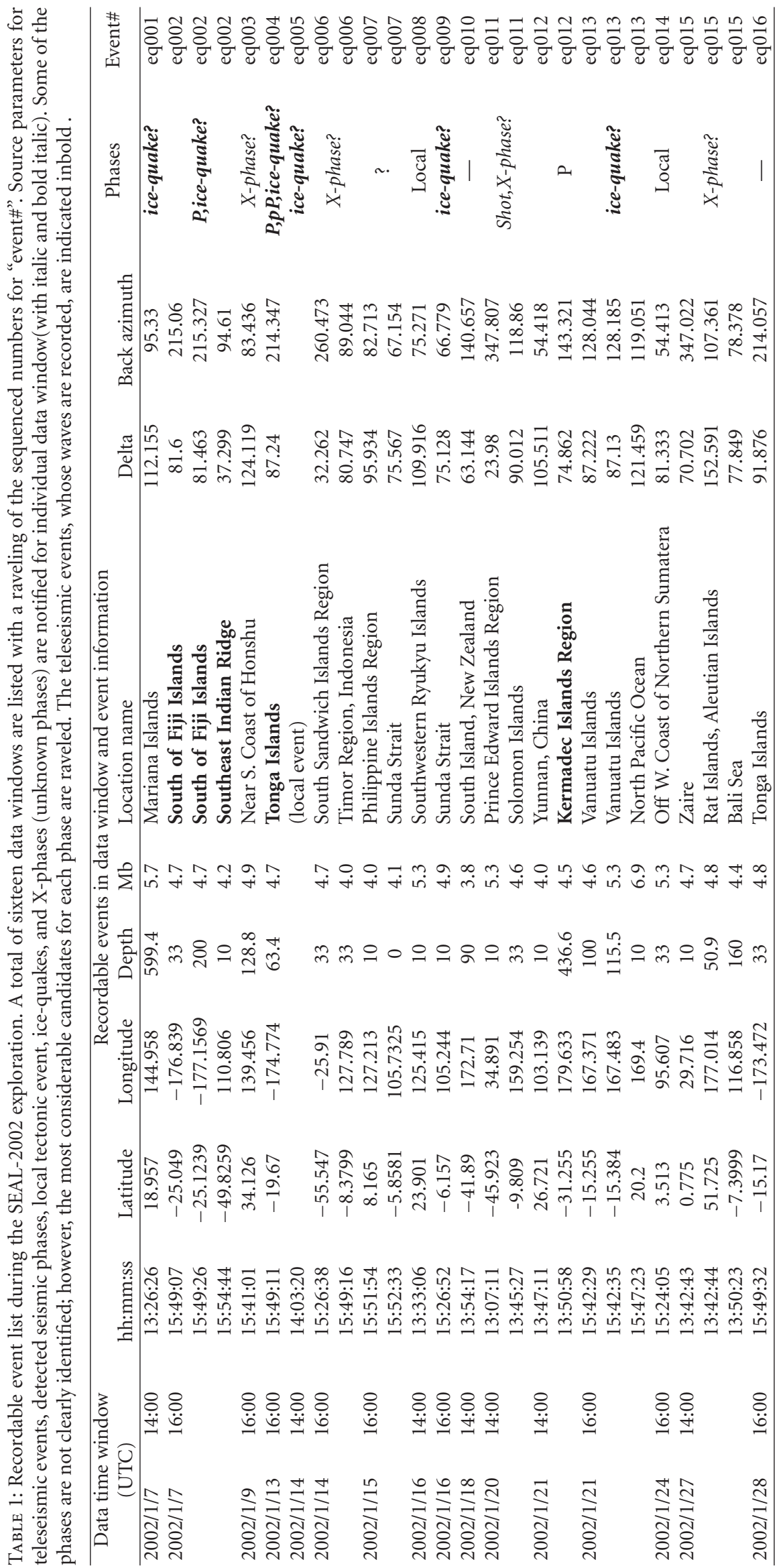




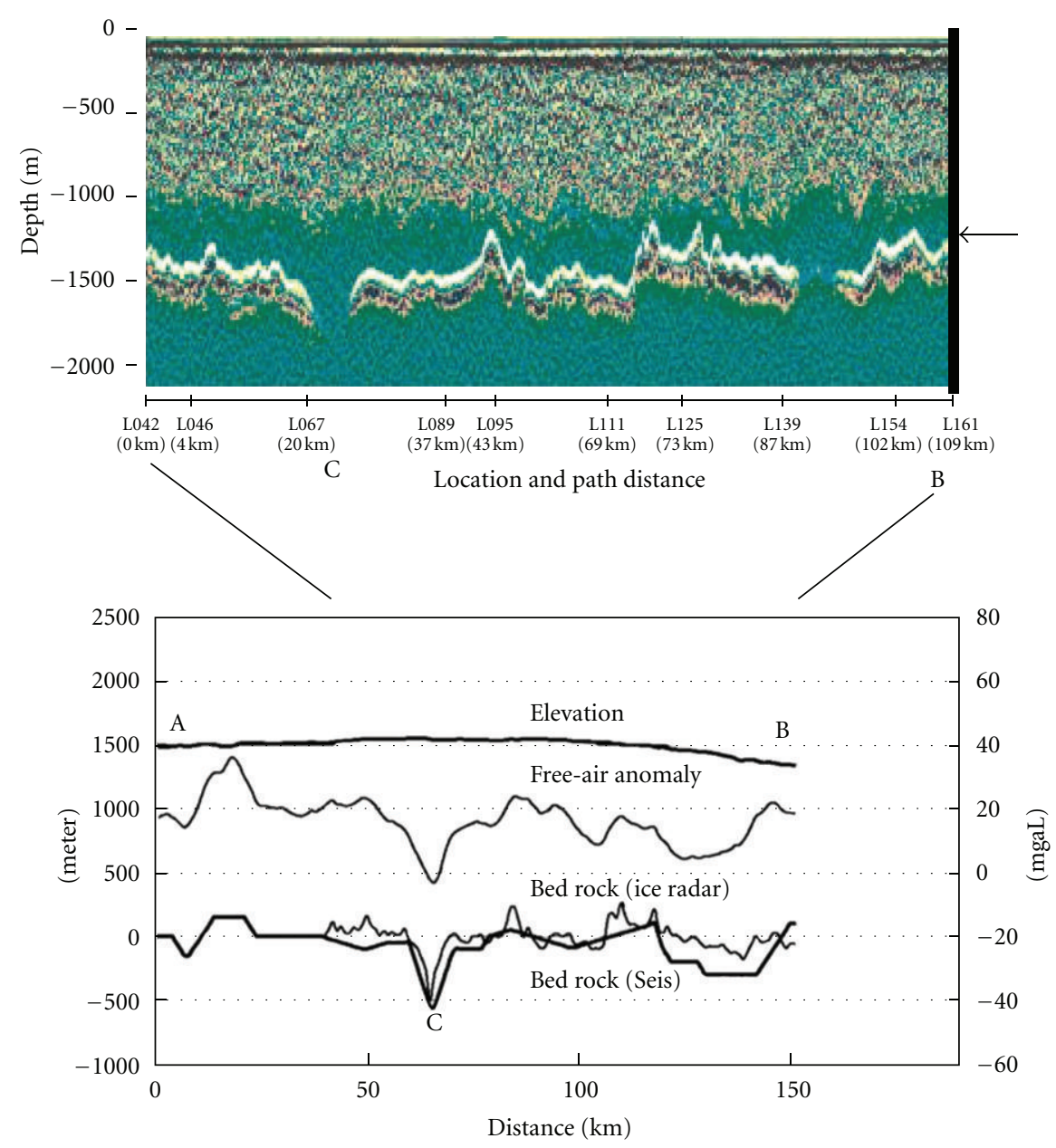

FIgure 2: Comparison of several geophysical data measured along the SEAL-2002 profile (A-C-B) in Figure 1; (lower) elevation of the icesheet surface (scale on the left side), free-air gravity anomaly (scale on the right side, modified after [11]), depths of the bedrock inferred from radioecho soundings [13], together with those from seismic travel-time analysis [11]. (upper) detail result from ground-traverse based radioecho soundings between the stations (L042)-C-B (modified after [13]). Several refection layers of the inner ice-sheet together with strong reflections from bedrock are identified. It is also noticed that there are areas in the profile without any reflections from the bedrock (around C, and the area between L139 and L154). In the areas, there is a possibility of water-filled layer spreading over the bedrock surface just as the valley structure (see the text for details).

8 to January 27, 2002. More detailed information on the observation specification is given by [11]. In spite of these short recording times, several kinds of seismic phases are identified and classified in Table 1.

Characteristic seismic waves from natural sources recorded in the experiments are evaluated by the following process. These obtained waves have a high signal-to-noise ratio in spite of the small magnitudes. These waves were classified into the following three categories: (1) teleseismic events; for example, those occurring in the Kermadec Is. Region, (2) local events extremely attributed by ice-quakes around the Lützow-Holm Bay Region, near the Mizuho Plateau, and (3) the source unidentified events by present information; which appeared to have the origin around Antarctic (here we call these phases as the "X-phases"). Regarding the teleseismic events, some phases are not clearly identified, however; the most considerable candidates for each phase are picked up in Table 1.
Figure 3 is an example of waveforms for a record section of artificial active source by dynamite explosive by the SEAL2002 exploration (shot no. SP3 (2002/01/20/14:01 UTC); event\#; eq011 in Table 1) together with band-pass filtered $(1.0-4.0 \mathrm{~Hz})$ waveforms for the same record section. A few local events that considered as the ice-quakes are recognized on the seismograms. The latest arrival phases in the lower have relatively long duration time in $20-30 \mathrm{~s}$, which might be considered as the large ice-quakes, otherwise the source unknown events (X-phases). Another waveform example containing teleseismic event (event\#; eq004; Tonga Islands) is presented in Figure 4. Many local events which appeared to be ice-quakes are clearly recognized with apparent slowness determined by different injection back-azimuths into the seismic profile.

An overview of the observed waveform signals indicates the difference in (a) coherency of signals and (b) amplitude fluctuations along the seismic profile. Here, we chiefly 


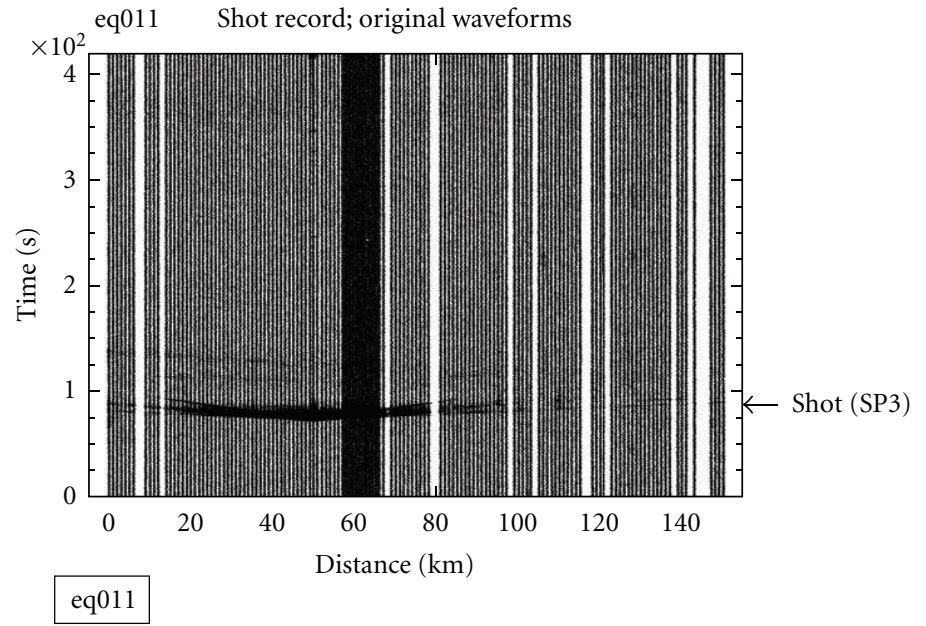

(a)

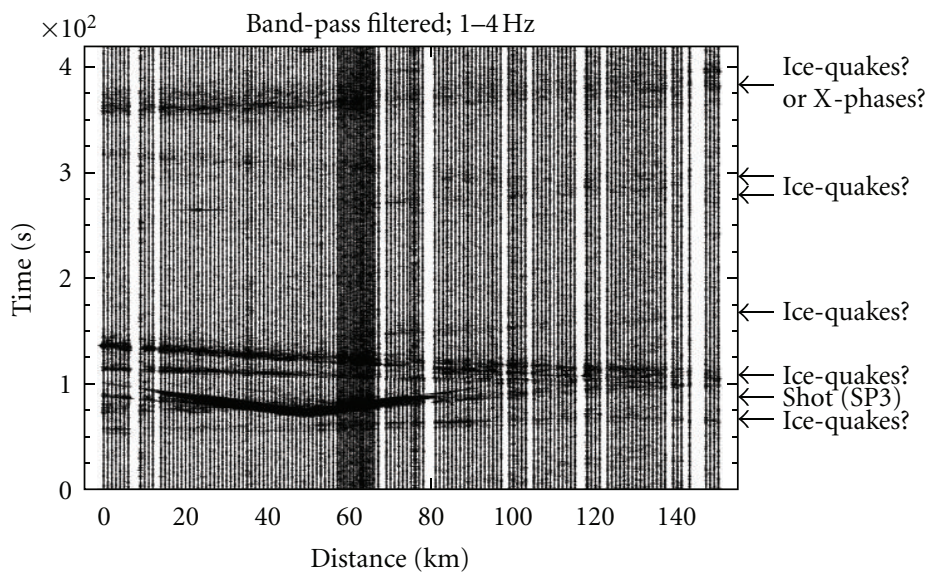

(b)

Figure 3: (upper) Original waveforms for record section of artificial active source by SEAL-2002 exploration (shot No. SP3 (2002/01/20/14:01 (UTC)); event\#; eq011). (lower) Band-pass filtered (1.0-4.0 Hz) waveforms of the same record section. Many local events which appeared to be the ice-quakes are recognized in the record. Starting time of the vertical axis is 14:00 (UTC) on January $20,2002$.

performed two analyses by a stacking method and a running spectrum in order to figure out the above two differences. First, we applied to several waveform dataset by a phaseweighted stacking (PWS) approach [17]. The PWS is a kind of nonlinear stacking procedure, and we use it instead of an ordinary linear stacking method. Each data point of a linearly stacked trace is weighted with an absolute value on average, as a sum of instantaneous phases for each trace. Thus, coherent signals throughout the seismic profiles can be constructively stacked and incoherent signals, even if some waveforms have larger amplitudes, result in a stacked signal with small amplitude due to the destructive sum of the phase components. The stacking procedure is performed by adopting variation in the slowness with a scanning interval of $0.001 \mathrm{~s} / \mathrm{km}$. We measure the slowness along the SEAL-2002 profile.

Second, against the several dataset, a running spectraum is taken by applying the FFT to a $2 \mathrm{~s}$ window (both sides of the window are hanning-tapered) with a time interval of $1 \mathrm{~s}$. Before calculating the spectrum, instrumental response is deconvolved from the original waveforms. By using these methods, we can achieve the discordances in both frequency and arrival times of the waveforms. Significant anomalous features are revealed in the waveforms of the stations just above the valley structure, as the topographic boundary between the ice sheet and the topmost crust. A difference in the PWS stacked waveforms, as well as the running spectra, is clearly obtained by applying to three kinds of waveforms of teleseismic, local, and unknown X-phase events.

\section{Teleseismic Events}

A hypocentral map of the plausibly detected teleseismic events during the SEAL-2002 exploration is shown in Figure 5. The teleseismic events shown in the map are the same listed in Table 1, and an expanded local map of the studied area on the Mizuho Plateau, East Antarctica, is inserted on the same figure. Five teleseismic events are successfully recorded (indicated in red in Table 1). Some 


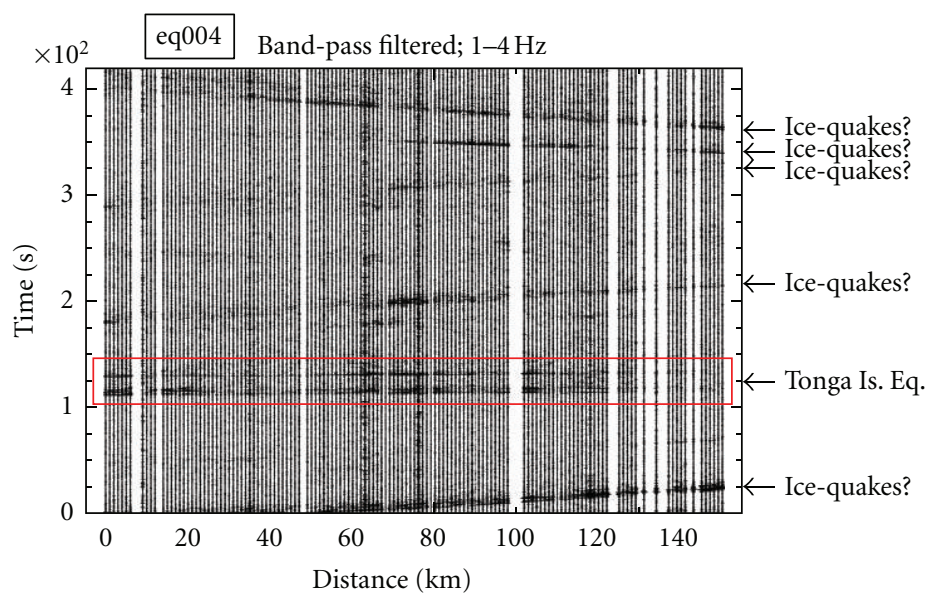

Figure 4: Band-pass filtered $(1.0-4.0 \mathrm{~Hz})$ waveforms of the record section including teleseismic event (event\#; eq004; Tonga Islands, indicated by red squared area). Many local events which appeared to be ice-quakes are clearly recognized. The vertical axis starts from 16:00 (UTC) on January 13, 2002. Seven minutes of the data length.

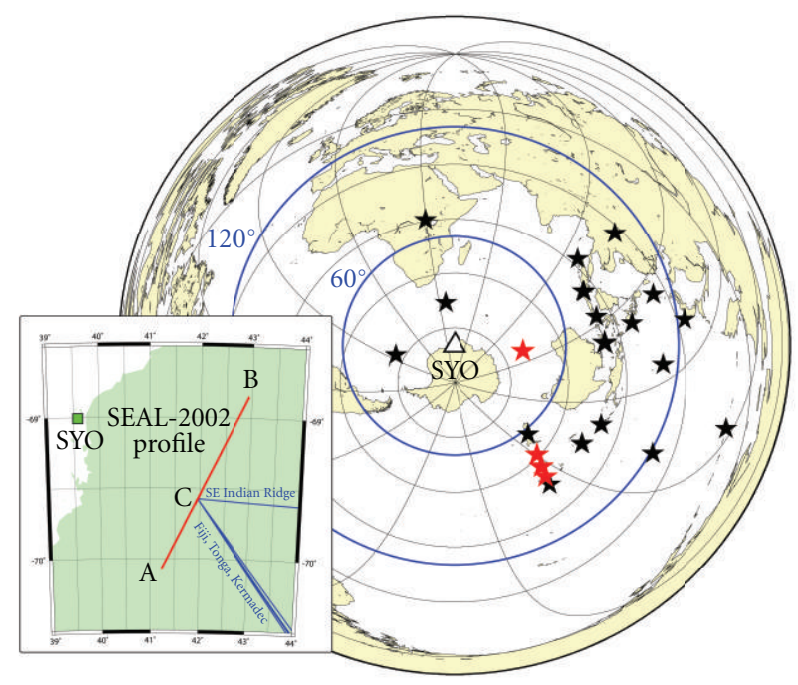

FIGURE 5: Hypocentral map of the teleseismic events during the SEAL-2002 exploration. Red/black stars indicate events whose waves can be identified/unidentified in the observed records, respectively (corresponding to Table 1). A black triangle indicates SYO. Blue circles show great circle distances of 60 and 120 degrees from SYO. (inset) An extended map of the studied area on the Mizuho Plateau (red line: SEAL-2002 profile, blue lines, incoming ray paths from observed teleseismic events).

events are located at larger epicentral distances over 90 degrees. Seismic phases expected to be recorded at the profile from such events are Pdiff and core phases of PKP family which have usually small amplitudes due to those longer wave paths within the earth. Therefore, it is expected that the events of smaller magnitude cannot be detected clearly on the seismographs in Antarctic stations.

Figure 6 indicates a teleseismic event from the Kermadec Is. Region (January 21, 2002, 13:50:58.8 (UTC), $4.5 \mathrm{mb}_{\mathrm{b}}$; event\#; eq012). The epicentral distance of the event to the SEAL-2002 profile is about $75^{\circ}$. The direct $\mathrm{P}$ waves can

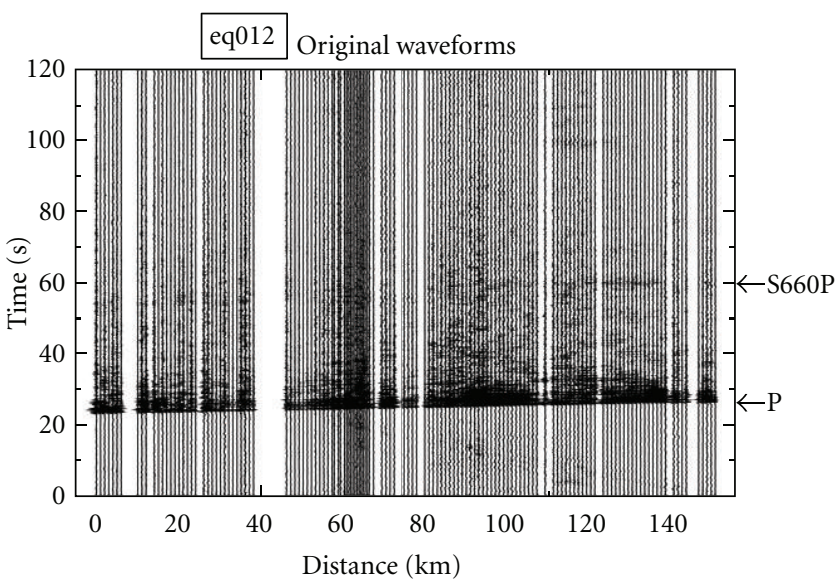

FIgURE 6: Record section indicating a typical teleseismic event occurred at Kermadec Is. $\left(\mathrm{m}_{\mathrm{b}}=4.5\right.$, Depth $=437 \mathrm{~km}$; event\#; eq012; modified after [23]). The vertical axis is the relative time measured from 14:01:30.0 (UTC) on January 21, 2002. Original (no filtered) traces for all station along the profile represent high signalto-noise ratio. Very strong signals during 20-30 s are composed of direct $\mathrm{P}$ and possibly reverberations from the ice-sheet. Faint signals found in 50-60s may be an S-P converted wave at the $660 \mathrm{~km}$ discontinuity just beneath the event (S660P).

be evidently and coherently seen throughout the recorded stations of the seismic profile, regardless of the degree of magnitude for the earthquake. The high signal-to-noise ratio of $\mathrm{P}$-waves for this event is achieved by high-sensitivity recording deployed at the Mizuho Plateau, which could give rise to the benefits of investigation not only to local structure of Antarctica but also to deep interiors of the Earth.

The teleseismic signals include a sufficient correlation of waveforms between the neighborhood stations and have frequency components lower than $2.0 \mathrm{~Hz}$ due to long-path propagation in the Earth's mantle. It is also identified clearly that the phase after $30 \mathrm{~s}$ from the first arrival appeared. 
This phase has almost the same slowness as that of the direct P-waves. Therefore, the origin of this later phase is presumably converted or reflected waves from discontinuity or heterogeneity located near the event source. A possible explanation of the later phase is the S-P converted waves at the $660 \mathrm{~km}$ discontinuity (S660P) beneath the earthquake. A travel time difference in stacked waveforms between the direct $\mathrm{P}$ and the later wave leads to a preliminary estimation of a converted depth at about $760 \mathrm{~km}$ based on a velocity model of IASP91 model [18]. The depth is deeper than those reported in the previous studies $(\sim 720 \mathrm{~km}[19,20])$ for the event region. Thus interpretations as seismic scatterers [21] or multiple discontinuities in the uppermost lower mantle [22] might be possible for the waves observed here. However, at the present, it is difficult to constrain the origin of the wave because the direction and length of the observation line are unfortunately unsuitable for slowness analysis which gives us additional and useful information of the origin.

Figure 7 represents the PWS images applied to teleseismic waves of the Kermadec Is. event (modified after [23]). The individual traces in the upper of Figure 7 are the lowpass filtered ones with a cutoff of $2.0 \mathrm{~Hz}$. A linearly stacked trace is calculated by searching the slowness that maximizes the amplitude of stacked direct P-waves. All the traces are aligned on the direct P-waves by applying the crosscorrelation method between each trace and the stacked $\mathrm{P}$ trace. The alignment of direct $\mathrm{P}$-waves represents a line of zero slowness, and also identified in the upper of Figure 7. The term of "slowness" here means a relative value compared with that of the direct P. Then we apply the PWS to the aligned traces by changing the slowness. The stacked traces are converted into envelopes by using the Hilbert transform and are plotted as a contour map in the lower of Figure 7.

Successive peaks with an interval of about $0.8 \mathrm{~s}$ between $25-29 \mathrm{~s}$ in Figure 7 are the direct P-waves. Since an incident angle of the direct $\mathrm{P}$-waves is close to almost vertical direction in case of this event, the interval of about $0.8 \mathrm{~s}$ can be interpreted as a two-way travel time within the ice-sheet layer beneath the seismic profile on the Plateau. Therefore, the five peaks following the direct $\mathrm{P}$-waves could be the reverberations within the ice-sheet. The thickness of the ice-sheet beneath the observation stations is approximately $1.5 \mathrm{~km}$ (Figure 2), which can explain the time intervals of the five peaks in later phases. The seismic source time function of this event is not identified, however, a deep focus event with small magnitude has assumed to be a simple source time function, and these peaks can be caused by the reverberations rather than complexity of the source. All the peaks have almost the same slowness as that of the direct P-waves.

Figure 8 represents the running spectra of three different time windows (from upper to lower; 24-26s, 25-27 s, and 26-28 s) applied to the Kermadec Is. Earthquake (event\#; eq012; modified after [23]). A dominant frequency is identified at about $2.0 \mathrm{~Hz}$ in these windows. It is clear that there is a significant gap in high energy volume around $2.0 \mathrm{~Hz}$ at about $65 \mathrm{~km}$, at where the valley structure is underlying beneath the ice-sheet (Figure 2). The observation stations on both sides of this gap (at around $59 \mathrm{~km}$ and $72 \mathrm{~km}$ ) appeared to receive the higher energies. It is also identified that the peaks

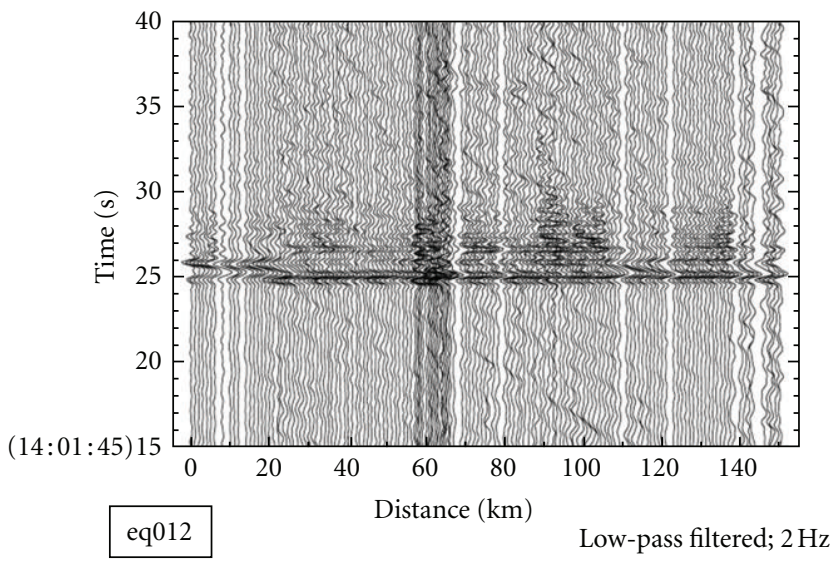

(a)

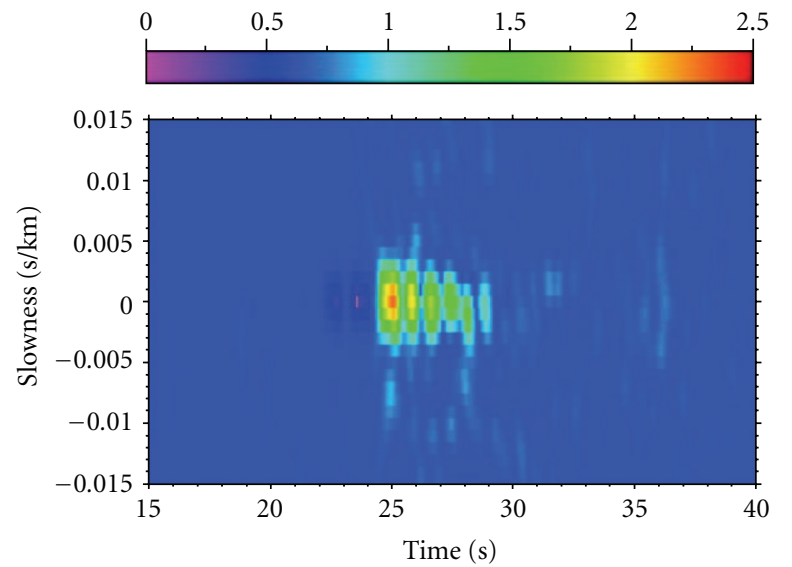

(b)

Figure 7: (upper) Time-expanded record section of the Kermadec Is. event (event\#; eq012), which are aligned on the onset of the direct $\mathrm{P}$ and are $2.0 \mathrm{~Hz}$ low-pass filtered. The pivot station is located at $74 \mathrm{~km}$. The vertical time-window contains the direct $\mathrm{P}$ and the core-reflected PcP. (lower) Contour map of the phase-weightedstacking (PWS) applied to all traces of upper in the same timewindow (modified after [23]).

at frequency about $3.0 \mathrm{~Hz}$ are located in the middle part of the seismic profile.

Another example of the record section containing simultaneously occurred teleseismic events is shown in Figure 9 (event\#; eq002). Several seismic phases from both the "Southeast Indian Ridge Earthquake" and "South of Fiji Island Earthquake" are duplicated recorded on the seismogram about the same times on January 7, 2002. Major teleseismic phases are clearly recognized at the time window around $100 \mathrm{~s}$. Such overlapping arrivals of waves can be disentangled by applying the PWS stacking procedure. Stacking the waveforms by changing values of slowness yields separation and identification of these events because of expected large difference in slowness between the events. In addition to the teleseismic events, several local events plausibly associated with ice-related dynamics are recorded in later phases. 


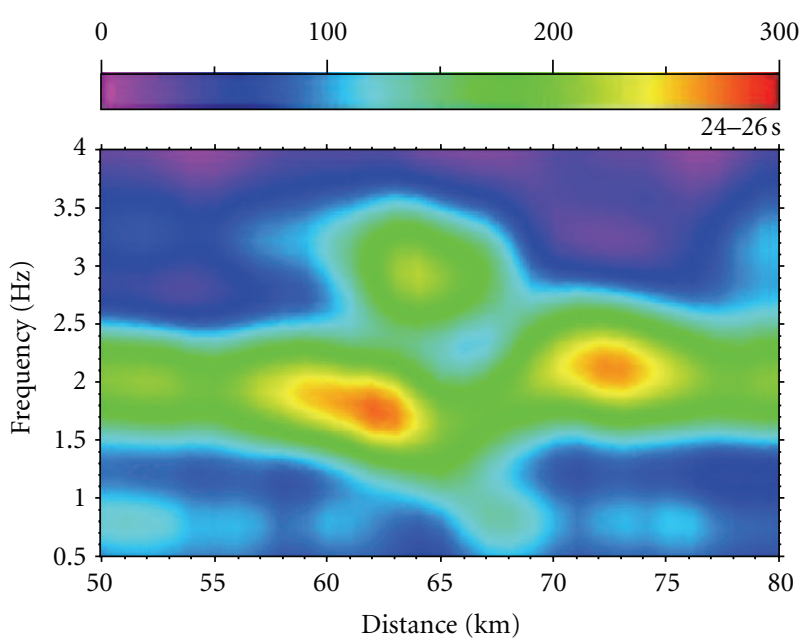

(a)
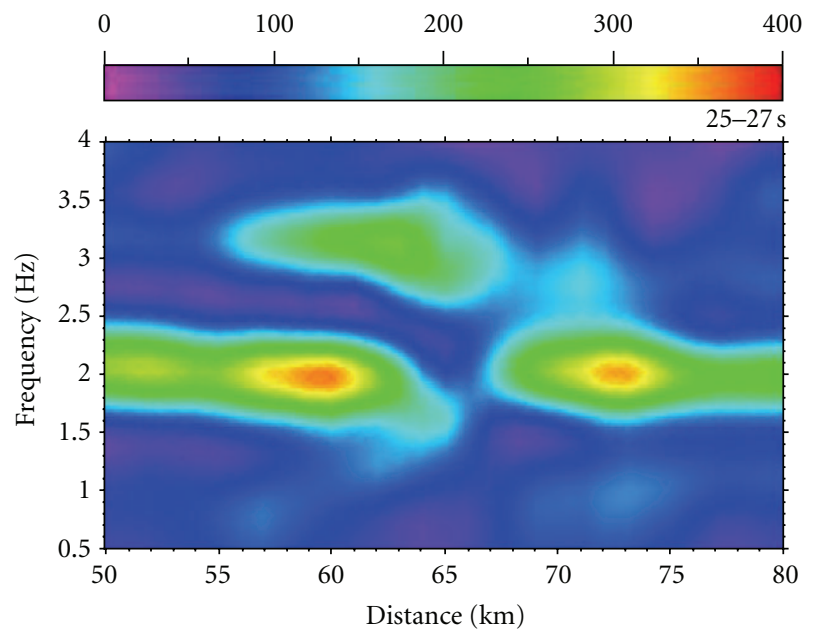

(b)

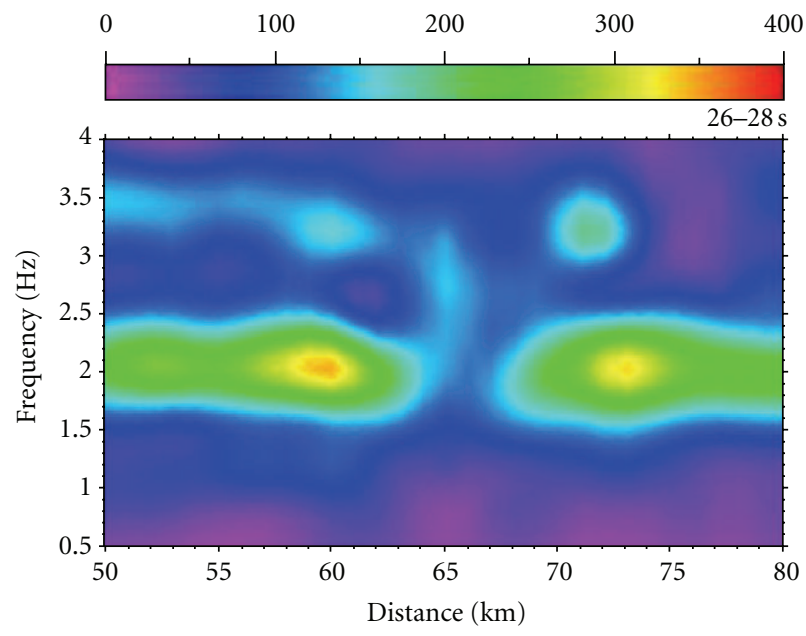

(c)

FIGURE 8: Contour maps showing amplitudes of seismic energies plotted in the frequency-distance domain for traces of the Kermadec Is. Earthquake (event\#; eq012; after [23]). Spectra are taken from the traces aligned on the direct P. Time windows are shown at the upper right of each plot (from upper to lower; 24-26 s, 25-27 s, and 26-28 s, resp.).
In spite of the short period of the SEAL-2002 exploration (three weeks) and short recording duration (7.5 minutes twice a day), clear observations from teleseismic events were obtained. As is listed in Table 1, all the events recorded here have rather small magnitude (smaller than 5.0) that is generally difficult to observe. These waves also deliver scientifically interesting information, that is, not only nearreceiver structural complexity but also global Earth's deep structures like a possibility of core phases, secondary waves from the mantle discontinuity/scatterer. The examples here suggesting further experiments of densely deployment of the short-period seismographs in Antarctica will provide us with fruitful data for investigations of both shallow structure of the Antarctica and deeper Earth structures.

\section{Ice-Quakes}

Seismic signals involving ice-related phenomena are socalled "ice-quakes" ("ice-shocks" for smaller ones) and are most frequently reported in association with glacially related mass movements of ice sheets, sea ice, tide cracks, and icebergs $[7,20]$. In West Antarctica, for instance, recent seismic and geodetic experiments have led to new discoveries related to the deformation of ice sheets environment. For example, daily tidally modulated, rapid slip episodes of the ice stream are discovered by microseismicity studies, and subsequently confirmed by GPS measurements $[6,24,25]$. The recent slip events also radiate long-period surface waves, which allows additional constraints to be placed on the source mechanism [24].

Local seismicity in 1987-2003 around the Lützow-Holm Bay Region is reported by [7]. The seventeen events were detected by local network deployed around the bay area. Almost hypocenters were located along the coast, apart from a few on the northern edge of the continental shelf. Several events may be large ice-quakes associated with seaice dynamics around the bay or in the southern ocean. The broadband seismographs at Syowa Station (SYO; 69.0 $0^{\circ} \mathrm{S}$, $39.6^{\circ} \mathrm{E}$ ), moreover, significantly recorded the characteristic waveforms associated with discharge events of large seaice volume from the Lützow-Holm Bay [8]. The longduration sea ice tremors represent spectral characteristics that distinguished them clearly from ordinary teleseismic and/or local tectonic events. A few sequences of harmonic overtoned signals, presumably associated with the merging of multiple ice volume at the bay.

As an example of local events relating to the ice-quakes, Figure 10 shows the original waveforms and the band-pass filtered $(4.0-8.0 \mathrm{~Hz})$ ones applying to the event\#; eq001. A significant number of local events are identified on the waveforms. It is noted that relatively strong and long duration wave packets recognized in 150-180 s do not match with the traveltimes of teleseismic phases. Moreover, when taking into account the positive slowness of these phases, the two phases with large amplitude may be a set of injected waves from the southern direction against the SEAL-2002 profile on the Mizuho Plateau. 


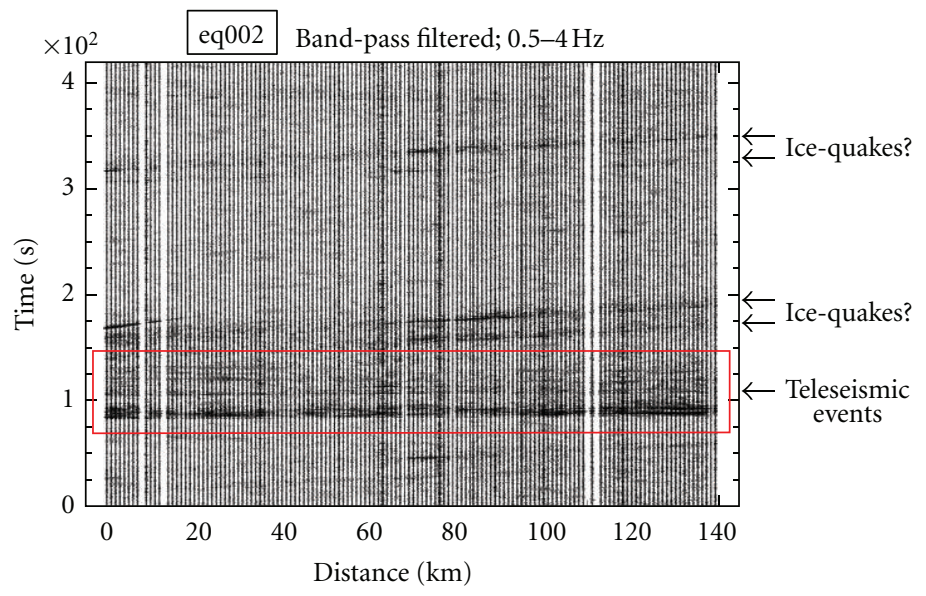

Figure 9: Band-pass filtered $(0.5-4.0 \mathrm{~Hz})$ waveforms of the record section containing multiple teleseismic events (event\#; eq002; Southeast Indian Ridge Earthquake, and South of Fiji Island Earthquake, January 7, 2002). Major phases are clearly identified at the time-window around 100s (red colored square area). Several local (ice-related?) events are recorded as the later phases, which are raveled as "ice-quakes?". Starting time of the slowness stacking analyses is indicated by red colored broken line (see the caption in Figure 10).

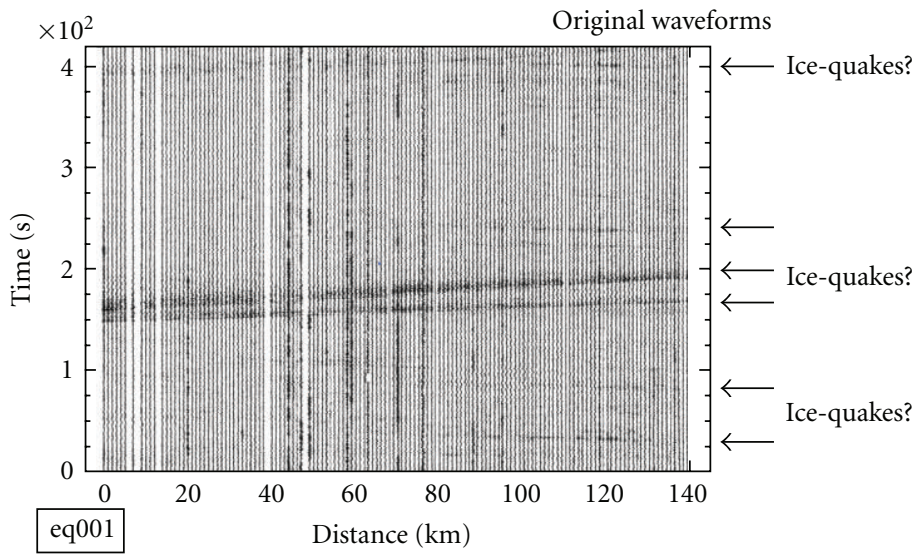

(a)

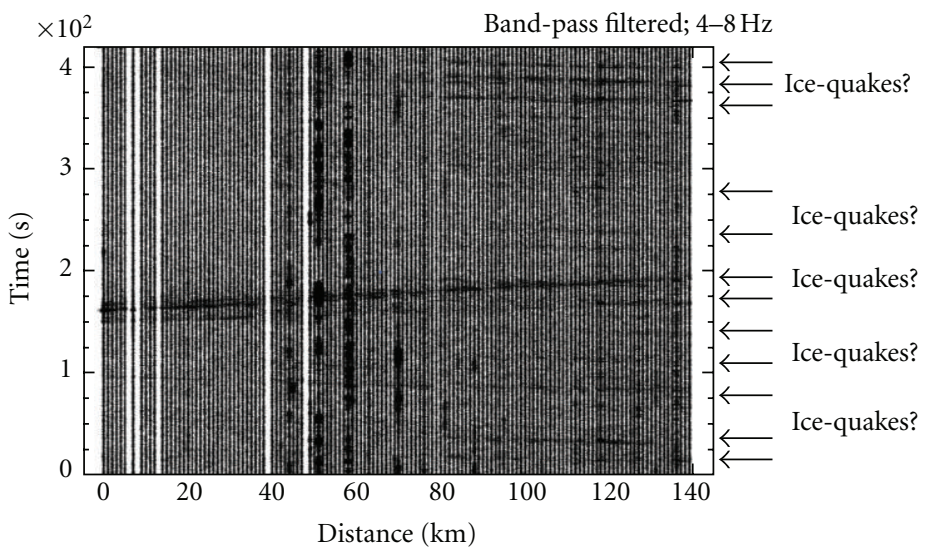

(b)

FIGURE 10: (upper) original waveforms for record section of local events, which appeared to be ice related events (ice-quakes) (event\#; eq001). (lower) Band-pass filtered $(4.0-8.0 \mathrm{~Hz})$ waveforms of the same record section. A significant number of local (ice-related) events are raveled as "ice-quakes?". 


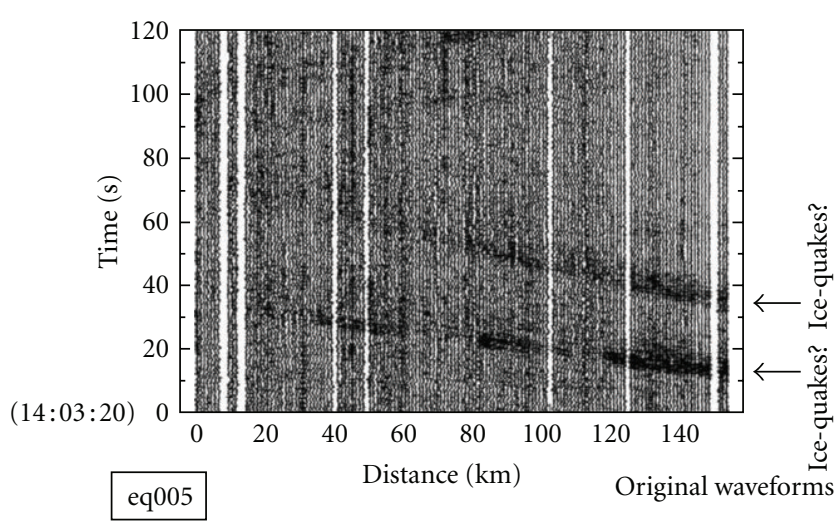

(a)

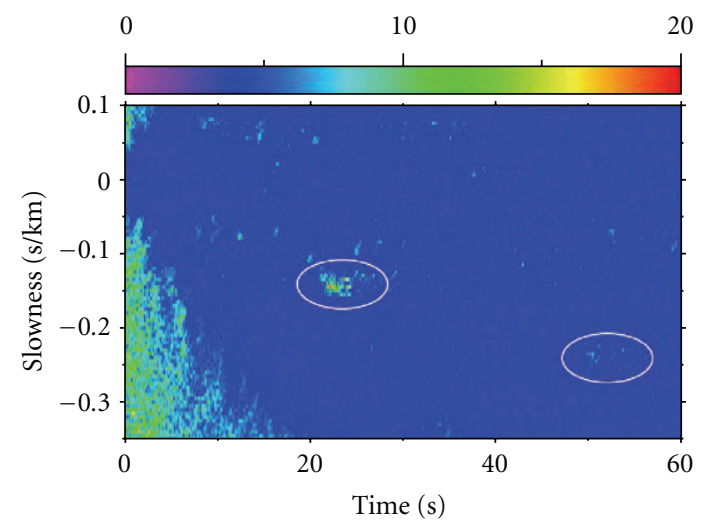

(b)

FIGURE 11: (upper) Recorded section for all the traces containing two large ice-quakes (event\#; eq005; after [23]). Two identical signals can be clearly traced. The vertical axis starts from January 14, 2002, 14:03:20 (UTC). (lower) Contour map of PWS applied to these ice-quakes in the same time-window (modified after [23]). Peaks corresponding to two obvious events in the upper are indicated by white ellipses: peaks at $(23 \mathrm{~s},-0.135 \mathrm{~s} / \mathrm{km})$ and $(51 \mathrm{~s}$, $-0.235 \mathrm{~s} / \mathrm{km}$ ). It is noted that high amplitudes found at the upper and lower left are artifacts caused by the PWS applied to zeroamplitude portions: since the zero amplitudes have the same value of phase components, a sum of the phase components should have a large value.

From these evidences, several signals traversing the observation profile may have common features: (1) including high-frequency components that are comparable with those of background noise, (2) containing relatively large slowness, and (3) large fluctuation of amplitudes and weak correlation of the waveforms along the seismic profile. These characteristics support an inference that local events such as ice-quakes occurred near the observation stations. According to as the above speculation, the locally originated phases are presumably involved with long-duration ice-dynamics occurred at the vicinity of studied area in Antarctica.

For another example, the upper of Figure 11 represents large ice-quakes detected on the recording stations of the SEAL-2002 profile (event\#; eq005; after [23]). Two obviously identical phases between 10 and 70 s arrive from the northern side of the observation profile (right of Figure 11), although the accurate direction of the incoming waves cannot be determined due to the line setting of the seismographs in the SEAL profile. Considering similarity of the lengths of wave trains and the difference in slowness, these two large phases may be a set of either $\mathrm{P}$ and $\mathrm{S}$ waves or direct and reflected waves from an ice-quake. In the figure, another two later phases with small amplitudes can be seen in time windows between 80 and 120 s. When considering the positive slowness, these two phases may be a set of waves from another pair of icequakes from the southern side of the observation profile.

The PWS contours of the same ice-quakes (event\#; eq005) are shown in the lower of Figure 11. Because of the incoherency of these ice-quakes, alignment on arrival cannot be done as above. Thus, the vertical axis in the lower of Figure 11 indicates the absolute slowness. Two peaks corresponding to the ice-quakes in the upper are seen at $(23 \mathrm{~s},-0.135 \mathrm{~s} / \mathrm{km})$ and $(51 \mathrm{~s},-0.235 \mathrm{~s} / \mathrm{km})$, respectively. As compared with the peaks in the lower of Figure 7, those in Figure 11 represent weak and scattered features. Since the PWS results enhance the signal that is coherent through the observation profile, we can tell that the waves generated by the ice-quakes are not coherent and show large fluctuations of the waveforms in distance range of about $100 \mathrm{~km}$.

\section{X-Phases (Unknown Events)}

Among the recorded events during the SEAL-2002 exploration, there are a few number of undefined events which are not likely both for the teleseismic events and for the local ice-quakes. This third category is named as unknown phases (hereafter referred to as the "X-phases"). A typical example of $\mathrm{X}$-phases is presented in Figure 12 (event\#; eq015) in which the SEAL-2002 profile and the three-component broadband waveforms at SYO station are shown. Continuous arrivals of coherent signals are clearly observed for a long duration approximately $100 \mathrm{~s}$. This coherency is the same as observed in the teleseismic waveform records (Figure 6). The slowness of these identical X-phases is almost zero, which implies that these signals come from a direction perpendicular to the observation profile.

These characteristic features of the slowness may indicate that these signals have the same sources as the teleseismic event. By referring to the worldwide earthquake catalogs (such as the ISC bulletin and USGS PDE listings), a candidate for the event might be the Rat Is. of the Aleutians Earthquake which occurred on January 27, 2002, at 13:42:44.4 (UTC). However, we present more details in the discussion section that the features of the X-phases cannot be explained only by this teleseismic event.

Although the sources of these signals are so far uncertain, we can find another interesting feature. The upper of Figure 13 represents a time-space variation in the envelope amplitudes of the band-pass filtered $(1.0-2.0 \mathrm{~Hz})$ seismograms (modified after [23]). A remarkable feature lies in a time-delay of the signal arrivals at around $65 \mathrm{~km}$ (at about $27,31,41,45,53 \mathrm{~s}$, etc.) compared with the corresponding arrivals found at other locations on the SEAL-2002 profile. Moreover, arrivals at about 27 and 31 s show large amplitudes at $65 \mathrm{~km}$ with a time delay of about $1 \mathrm{~s}$. This is not identified 


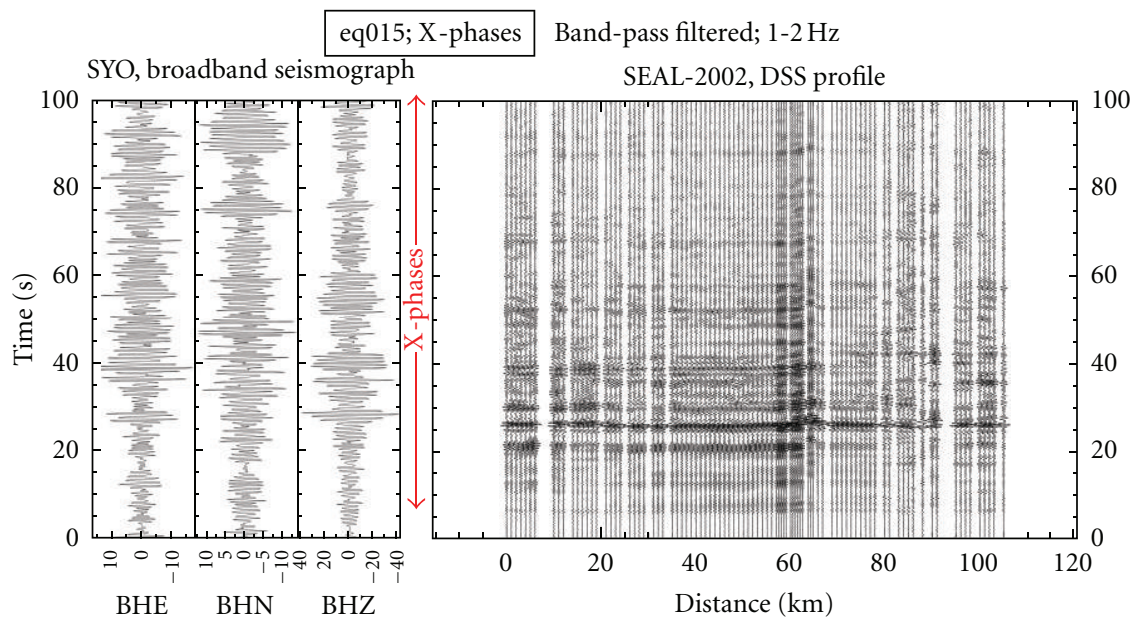

FIgURE 12: Record section showing the X-phases (event\#; eq015) with a band-pass filter (1.0-2.0 Hz). Vertical axis starts from January 27, 2002, 14:02:30 (UTC). (left) Three-component broadband seismograms at SYO (right) SEAL-2002 recordings.

in other frequency bands and is also not found in the teleseismic waveform records. The distance of $65 \mathrm{~km}$, as mentioned before, is located just above the valley structure of the bedrock topography (Figure 2).

The lower of Figure 13 demonstrates the PWS stacking of the same X-phases (event\#; eq015). As in the case of the Kermadec Is. event (Figure 7), we utilize the relative slowness with respect to the first arrival of the X-phases. Consecutive arrivals with high coherency are found for about $100 \mathrm{~s}$ after the onset. This long duration is not found in the cases of either the Kermadec Is. event, or the ice-quakes. The slownesses of all the arrivals are almost the same. This implies that these wave energies reach the observation profile with the same incident angle and the back-azimuth.

The dominant frequency of the X-phases (event\#; eq015) is found to be $2.0 \mathrm{~Hz}$, similar to the teleseismic events. In addition to the gap of $2.0 \mathrm{~Hz}$ at about $65 \mathrm{~km}$, we can identify a strange feature appeared in the spectra, which is not found in the teleseismic event. The clearly recognized gap of $2.0 \mathrm{~Hz}$ at $65 \mathrm{~km}$ turns into a peak of $1.5 \mathrm{~Hz}$ with a delay of only one second (middle and bottom in Figure 14). This peak of $1.5 \mathrm{~Hz}$ corresponds to the energy peak at $(27 \mathrm{~s}, 65 \mathrm{~km})$ in the upper of Figure 13.

Another example of the X-phases is demonstrated in Figure 15 (event\#; eq006). The band-pass filtered $(0.5-4.0 \mathrm{~Hz})$ waveforms of the record section image significantly show the existence of X-phases, together with several local events (ice-quakes). The long-time durations with high amplitudes in the X-phases are evidently identified at the time-window after $300 \mathrm{~s}$. Here, when considering the negative slowness of the X-phases, they may be injected from the northern direction against the seismic profile. In addition, several local (ice-related) events are recorded as the earlier phases in the same seismograms.

\section{Discussion}

In order to identify the location of occurrence of the unknown X-phases, we try to compare the waveforms recorded by the SEAL-2002 exploration with a threecomponent broadband seismograph at SYO in the LützowHolm Bay, near the Mizuho Plateau. Figures 12 and 15 are the comparison of the (event\#; eq015) and (event\#; eq006), respectively. When looking at a glance, however, we cannot identify the significant difference in the arrival times between SYO and the stations at the most northeastern end of the SEAL-2002 profile. In particular, the signal-to-noise ratio at SYO for (event\#; eq006) is poor for resolution, so as to judge the difference in arrival times. In the following few paragraphs, therefore, we focus on the event\#; eq015 for more detailed discussion.

A remarkable feature of the X-phases (event\#; eq015) is that successive arrivals of waveform energy have almost zero slowness for about $100 \mathrm{~s}$ after the onset (Figure 13). A candidate of the teleseismic event might be the Rat Is. (Aleutians) earthquake (included in the event\#; eq015; Table 1). However, for three reasons in the following, we cannot state that only the teleseismic event is the source that produced the X-phases.

First reason is that the long duration of $100 \mathrm{~s}$ cannot be explained by only teleseismic event. Epicentral distance from the Rat Is. (Aleutians) event to the center of the SEAL-2002 observation profile is about $152^{\circ}$. At the distance, we can observe at most 9 waves of PKP phase, that is, three branches (df, bc, and ab) and those depth phases (pPKP and sPKP). These waves are expected to be arrived in the first half of the duration (about 0-40 s in Figure 14). Actually, some peaks in Figure 14 match a part of expected PKP phases but not for all. However, there is no candidate phase for the latter half (40$100 \mathrm{~s}$ in Figure 14). If the long duration is caused by complex structures beneath the observation line, similar phenomenon would appeared in the cases for other recordings of natural teleseismic events observed here. For example, the recordings of the P-wave from the Kermadec Is. Event (Figure 6, Event\#; eq012) do not show such long durations. This discrepancy is hard to be explained by a difference in incoming direction between the events. For the Rat Is. event, the back-azimuth from the center of the seismic profile on the Mizuho Plateau 


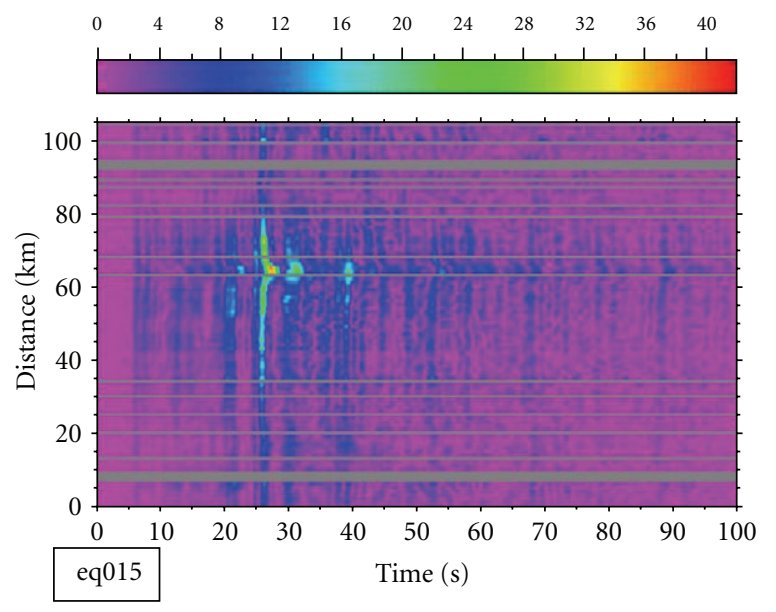

(a)
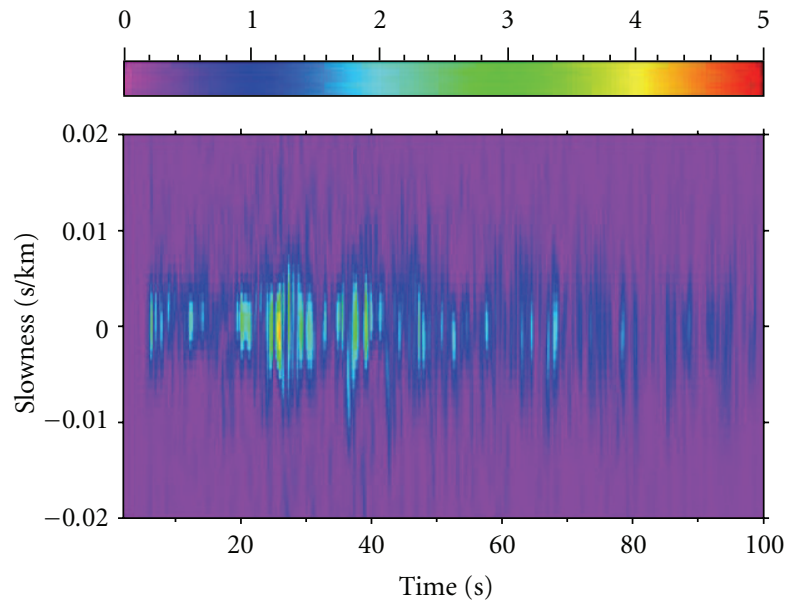

(b)

Figure 13: (a) Contour map showing envelope amplitudes of bandpass $(1.0-2.0 \mathrm{~Hz})$ filtered traces of the X-phases (event\#; eq015). Traces with low signal-to-noise ratios are not used here and are colored in gray. Since the traces here are band-pass filtered, the number of traces with high signal-to-noise ratio is different from that in Figure 12. Color scale is arbitrarily set to see an apparent amplitude variation within the map. (b) Same as in Figure 7 but for the X-phases (event\#; eq015).

is $107.4^{\circ}$, and the incident angle to the boundary between ice-sheet and topmost crust ranges from $4.6^{\circ}$ (PKPdf) to $13.4^{\circ}$ (PKPab), respectively. They are $143.3^{\circ}$ and $18.0^{\circ}$ for the direct P-waves of the Kermadec Is. event. If we consider the raypaths of the PKPs of the Rat Is. event and the direct P of the Kermadec Is. event to a station on the SEAL-2002 seismic profile, the piercing points of these waves to the boundary have a difference in horizontally only a few hundred meters. This distance is much smaller than the horizontal length of the complex structures beneath the observation line (e.g., valley structure, which is approximately $10 \mathrm{~km}$ (Figure 2)). Therefore, we cannot expect that the different kinds of waveforms are generated by a complex topography of the bedrock boundary for the Rat Is. event and the Kermdec Is. event.

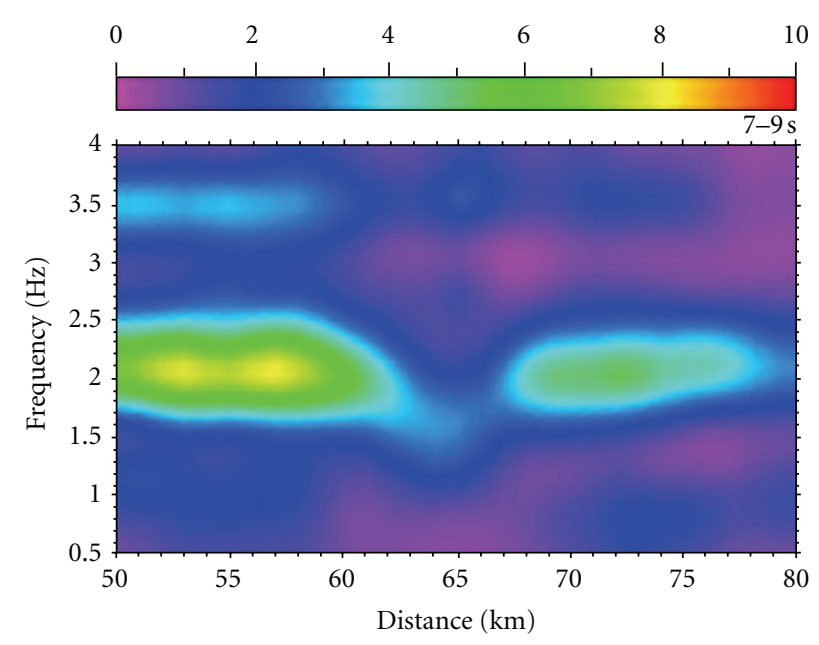

(a)

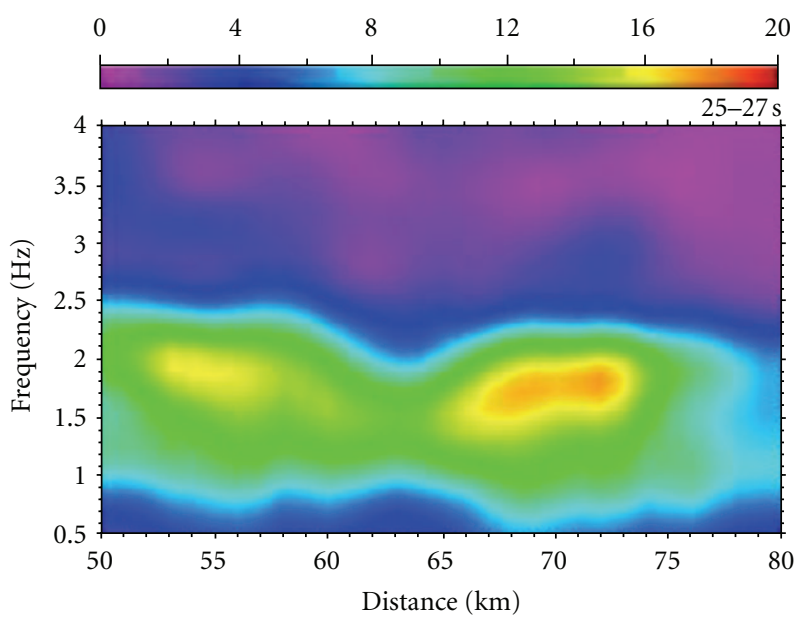

(b)

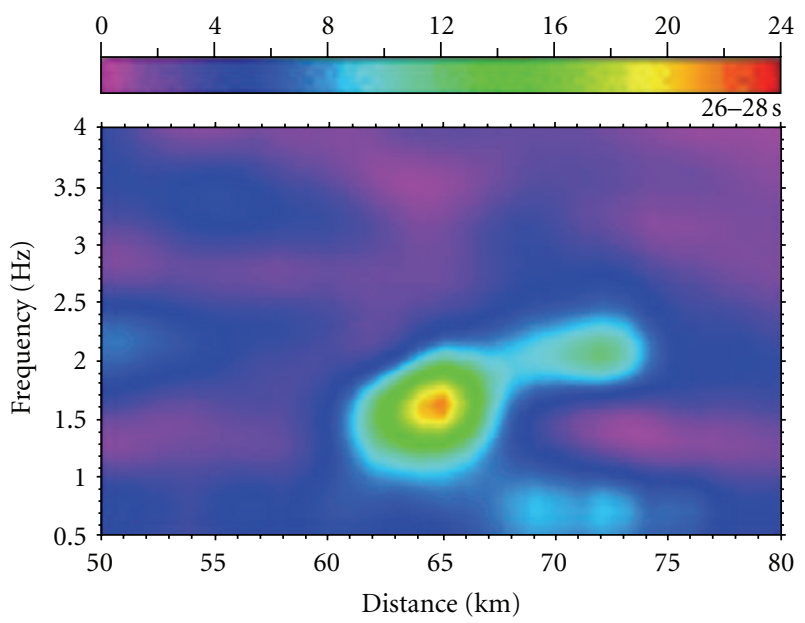

(c)

FIgure 14: Same as in Figure 8 but for the X-phases (event\#; eq015). Time windows are shown at the upper right of each plot (from upper to lower; 24-26 s, 25-27 s, and 26-28 s, resp.). Top and middle show the gap of high energy of $2.0 \mathrm{~Hz}$ at around $65 \mathrm{~km}$, and the bottom shows the peak of $1.5 \mathrm{~Hz}$ just a second late after the time window showing the gap in the middle. 


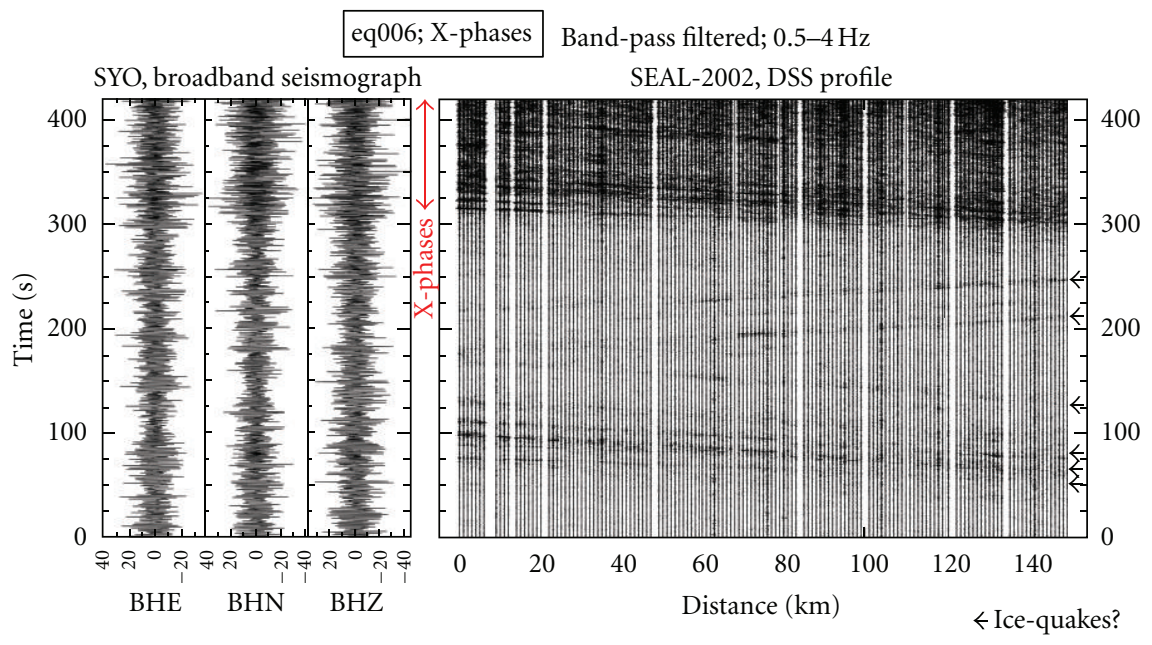

Figure 15: Band-pass filtered $(0.5-4.0 \mathrm{~Hz})$ waveforms of the record section for X-phases together with local events (ice-quakes) (event\#; eq006). (left) Three-component broadband seismograms at SYO (right) SEAL-2002 recordings. The unknown originated X-phases are evidently identified at the time-window after $300 \mathrm{~s}$. Several local (ice-related?) events are recorded as the former phases, which are raveled as "ice-quakes?".

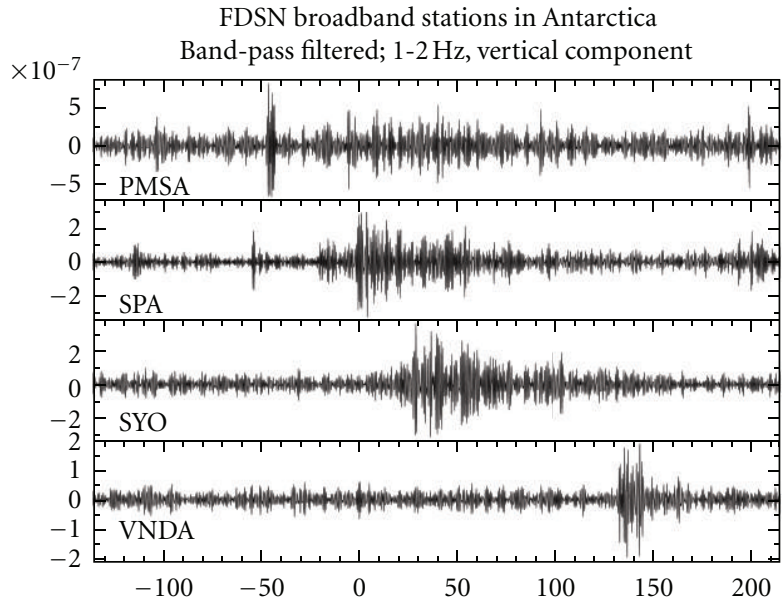

(a)

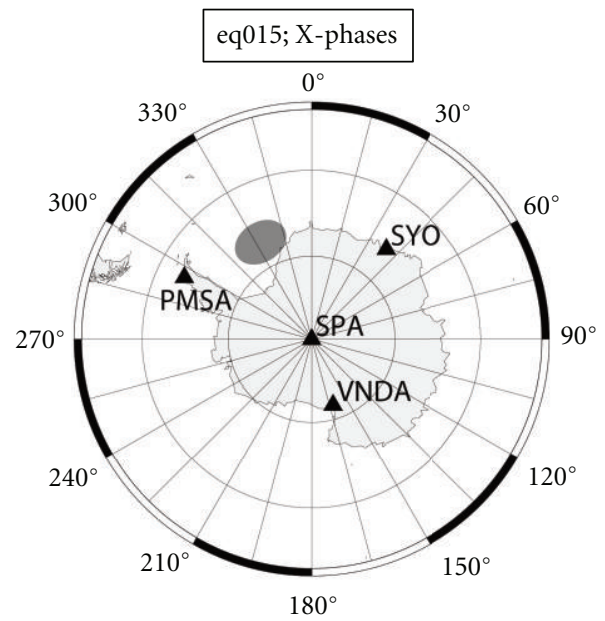

(b)

Figure 16: (left) Comparison of the X-phases (event\#; eq015) recorded by four existing FDSN stations in Antarctica (from top to bottom; PMSA, SPA, SYO, and VNDA). All waveforms are band-pass filtered (1.0-2.0 Hz) vertical component. (right) Location of the four FDSN stations. Shaded ellipse indicates a possible source for the energies in the waveforms as the X-phases.

Second reason is successful recordings with long durations similar to eq015. As listed in Table 1, we categorize three recordings (Event\#; eq003, 006, and 011) as the Xphase. They show successive arrivals of energies with at least several ten seconds; however, a beginning or ending of wave duration is out of a recording range for each three due to the short duration of seven and half minutes for each recording,. For these three, there is no possible teleseismic earthquake unlike the Rat Is. Event for eq015, leading to an origin other than teleseismic events. Resemblance of the waveforms of eq015 and additional 3 recordings (eq003, 006, 011 and 015) can categorize these 4 into a phenomenon caused by an unidentified origin.
Third reason is a significant difference in the amplitudes of seismic energies in the frequency-distance domain, between the X-phases (Figure 14) and the Kermadec Is. Event (Figure 8 ). The clear gap of $2.0 \mathrm{~Hz}$ in the middle part of the seismic profile is identified in both two events. However, the peak of $1.5 \mathrm{~Hz}$ (delayed about a second after the gap) is seen only in the X-phases and the peak of $3.0 \mathrm{~Hz}$ (which is not time delayed) is identified only in the Kermadec Is. Event.

These reasons may lead to a conclusion that the X-phases would not be the waves of teleseismic events. Note that, of course, we cannot discard a possibility that PKP phases overlap with the phenomenon for eq015. Since back-azimuth of $107.4^{\circ}$ of Rat Is. Event for eq015 is almost perpendicular 


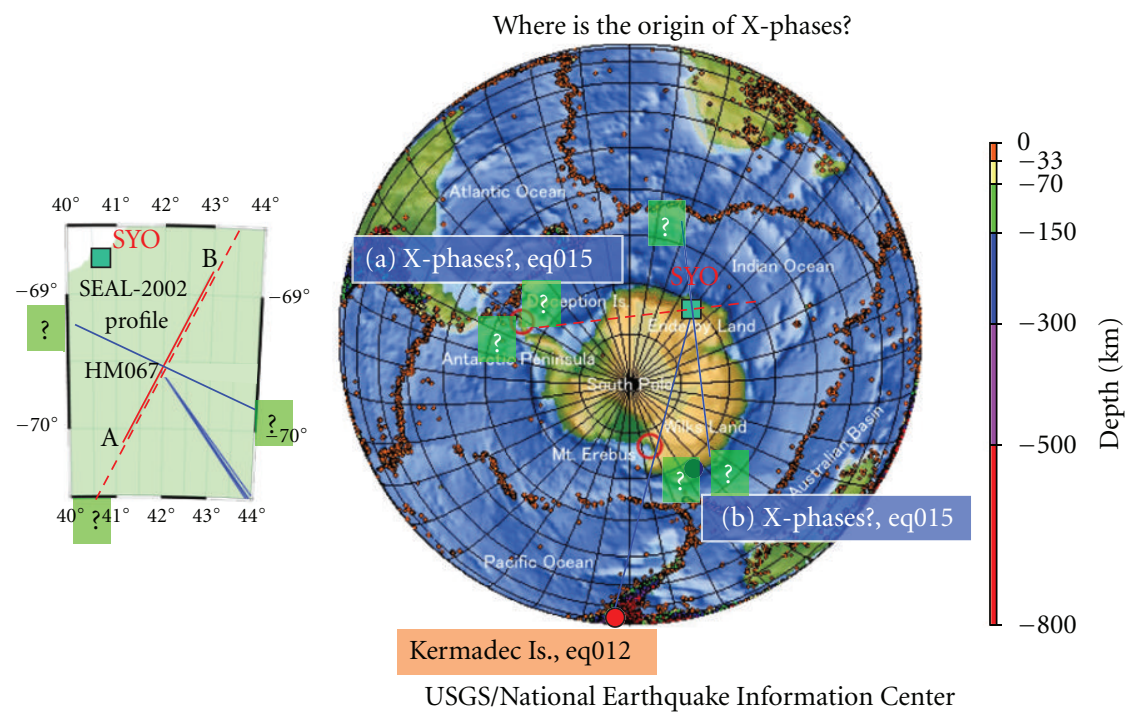

FIGURE 17: Plausible candidates of the location for X-phases (event\#; eq015), overprinting on the background seismicity (by USGS/NEIC) around Antarctic Plate. Hypocenter of the Kermadec Is. earthquake (event\#; eq012) is also presented for comparison.

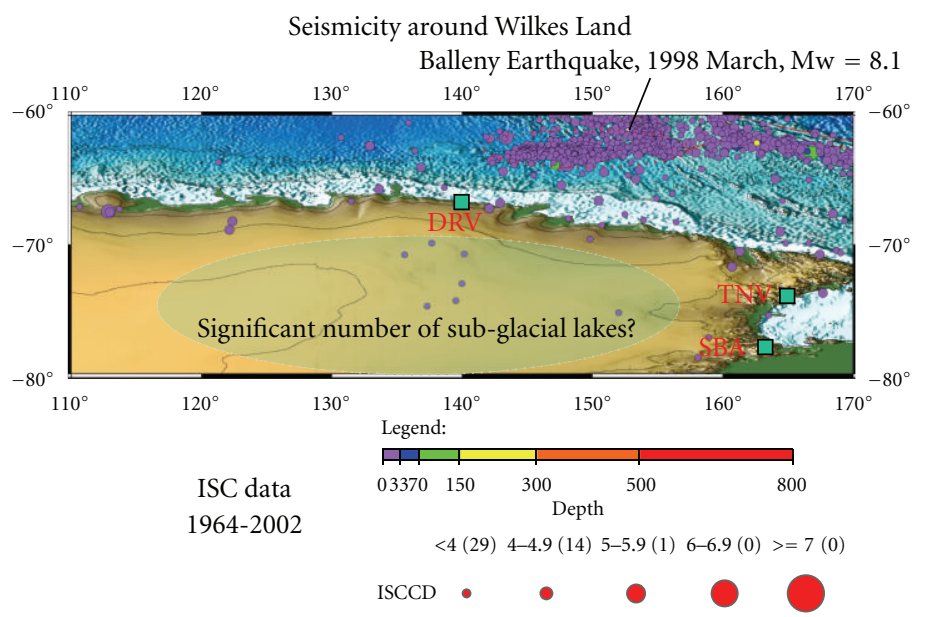

FIGURE 18: Globally complied seismicity around Wilkes Land, East Antarctica for 1964-2002 by the International Seismological Centre (ISC). The aftershock area of the large Balleny Island Earthquake (1998 March, Mw = 8.1) is included on the map in the Antarctic Oceanic Plate. A complexity of the surface bedrock structure might be influenced by tectonically weakened upper crust along with the present mobile belts, forced by the Tasmania microplate. It is also noticed that there is significant a number of subglacial lakes and occurrence of local seismic activities including ice-quakes.

to the direction of the SEAL-2002 seismic profile, separation and identification of PKP phases by slowness analysis are not possible. Therefore, the waveforms of eq015 might be a composite of the unidentified phenomenon and a remarkable success of recordings of PKP phases from smallmagnitude event.

Another striking phenomenon is recognized in Figure 13. In addition to a delay of the arrivals at around $65 \mathrm{~km}$ just above the valley structure in the middle of SEAL-2002 profile, we can find, by close inspection, a small arrival without delay just before the late arrival, at about $25 \mathrm{~s}$. Such normal arrivals are also found at $6 \mathrm{~s}$ (onset) and 35-40 s, respectively. The Xphases consist of the wave packets with normal and delayed arrivals. It is clear from the records of the Kermadec Is. Event (event\#; eq012) that the P-wave arrivals are not delayed at about $65 \mathrm{~km}$. Therefore, the normal arrivals of the X-phases may be the P-waves, but the delayed arrivals might not be the P-waves. A possibility could be the generation of the $\mathrm{S}$-waves. Whether the $\mathrm{S}$-wave arrival is delayed at around $65 \mathrm{~km}$ or not can be clarified by checking the dataset of Swave arrivals of the Kermadec Is. Event. Unfortunately, the $\mathrm{S}$-wave arrivals are out of range of the recording period in the SEAL exploration data. If the above hypothesis is valid, it is plausible that the origin of the $\mathrm{X}$-phases is not a teleseismic event but a regional event around Antarctica.

Next we examine the broadband data distributed in the wide area of Antarctica, as contribution to the Federation of Digital Seismographic Networks (FDSN; [26]). Figure 16 


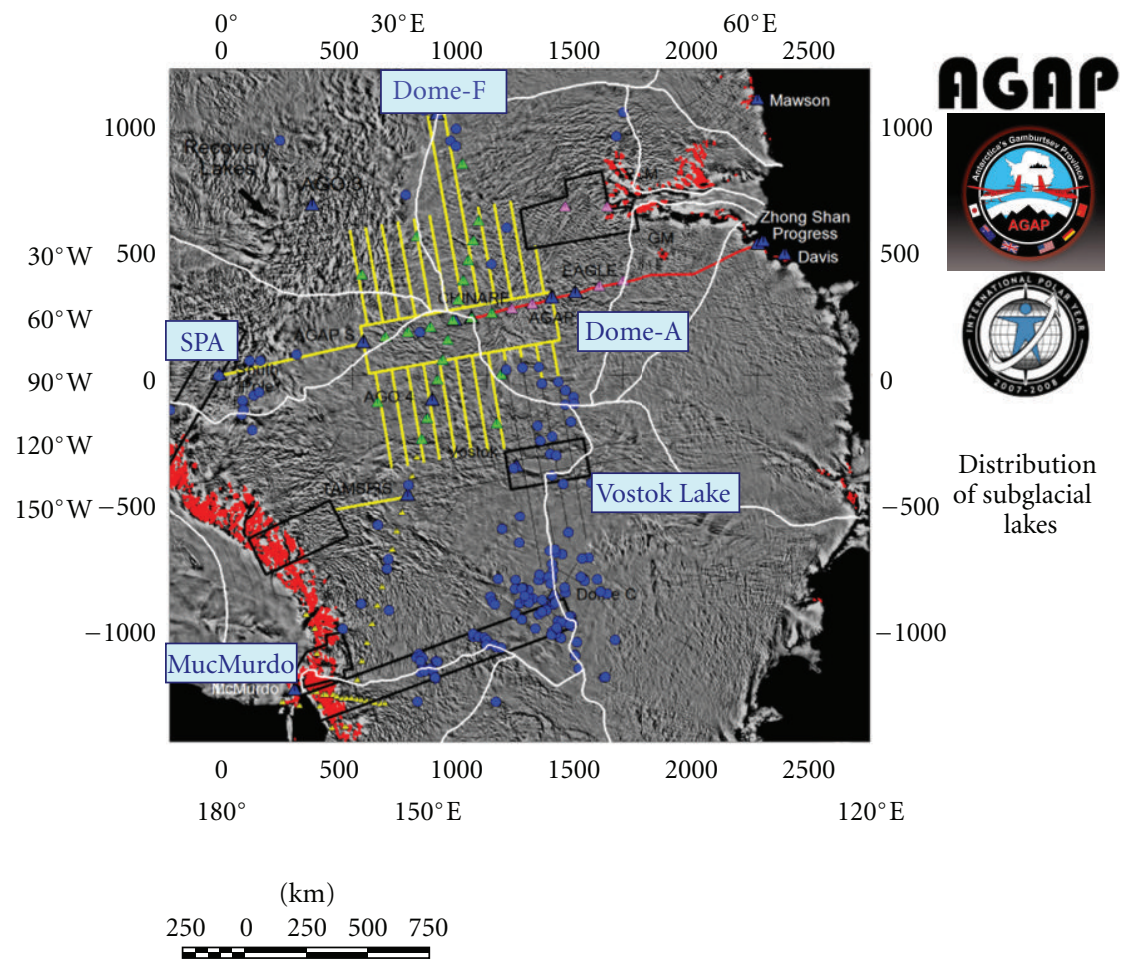

Polar stereographic projection standard parallel $71^{\circ} \mathrm{S}$

Figure 19: Distribution of subglacial lakes (blue solid circles) in wide region of Wilkes Land, East Antarctica. The target areas for several geophysical surveys including the International Polar Year (IPY 2007-2008) campaign period are demonstrated, by yellow lines (air-borne geophysics by AGAP), red line (Chinese traverse by AGAP), green triangles (seismic stations by AGAP) and several black circulated areas (the other air-borne geophysics projects). (The map is by courtesy of Professors R. Bell and M. Studinger; http://www.ldeo.columbia.edu/ mstuding/AGAP/). The formation, distribution and stability of subglacial lakes tell us the fundamental question how the tectonic processes control them.

represents waveforms recorded by four existing FDSN stations (PMSA, SPA, SYO, and VNDA) in a time range corresponding to the X-phases (event\#; eq015). Instrumental response of each station is removed from the original waveform and a band-pass filter $(1.0-2.0 \mathrm{~Hz})$ is applied for comparison with Figure 12. We assume energies in the waveforms as the $\mathrm{X}$-phases though some ambiguity remains for the identification. The arrival times of the $\mathrm{X}$ phases, comparing maximum amplitudes in each waveform, indicate the earliest for the station PMSA $\left(64.8^{\circ} \mathrm{S}, 64.0^{\circ} \mathrm{W}\right)$ in Antarctic Peninsula. Then, the ordering is recognized as from SPA (Amundsen-Scott South Pole Station), SYO, and VNDA $\left(77.5^{\circ} \mathrm{S}, 161.9^{\circ} \mathrm{E}\right)$ in the Terra Nova Bay of West Antarctica. A determination of a hypocenter by using the arrival times as P-wave indicates a source region of the Weddell Sea (shaded ellipse in the map of Figure 16). Note that the determination is not well constrained and leads to a wider area with large errors due to the difficulty of picking and the ambiguity of the identification as the X-phases. Thus, we propose here, as a preliminary and tentative suggestion, that a location of the X-phases (event\#; eq015) is speculated at the Weddell Sea and near the Antarctic Peninsula region (Figure 17, (a)).

In contrast, on the basis of PWS images of the X-phases (Figure 13), the incident angle to the SEAL-2002 profile is almost perpendicular direction (Figure 17) so as to explain the zero slowness of the incident wavelets. Therefore, when assuming the horizontal injection from the Earth's surface, two directions are considered from both the back-azimuths in eastern side (inside East Antarctic continent) and in western side (inside Indian Ocean, within Antarctic Plate to oceanic ridges) (Figure 17, (b)). As a possibility of the origin of X-phases (event\#; eq015) may be the intracontinental earthquakes, such the regional events around Antarctica are compiled in recent one decade $[2,3]$.

Around continental area in East Antarctica from $90^{\circ} \mathrm{E}$ to $180^{\circ} \mathrm{E}$, seismicity is low in an average by general understanding. The Wilkes Land, in contrast, has been identified as the most tectonically active region among the Antarctic (Figure 18). Poorly located earthquakes in Wilkes Land are lined from north to south along the $140^{\circ} \mathrm{E}$ longitude, crossing several subglacial highlands such as the Resolution, the Adventure, and the Belgica [1, 3, 27]. It is also noticed that there is a significant number of subglacial lakes (Figure 19) in this area; then it can be considered a relation to produce the occurrence of local seismic activities. The formation, distribution and stability of subglacial lakes could give rise to the fundamental question how do the tectonic processes control the existence of the lakes [28]. The 


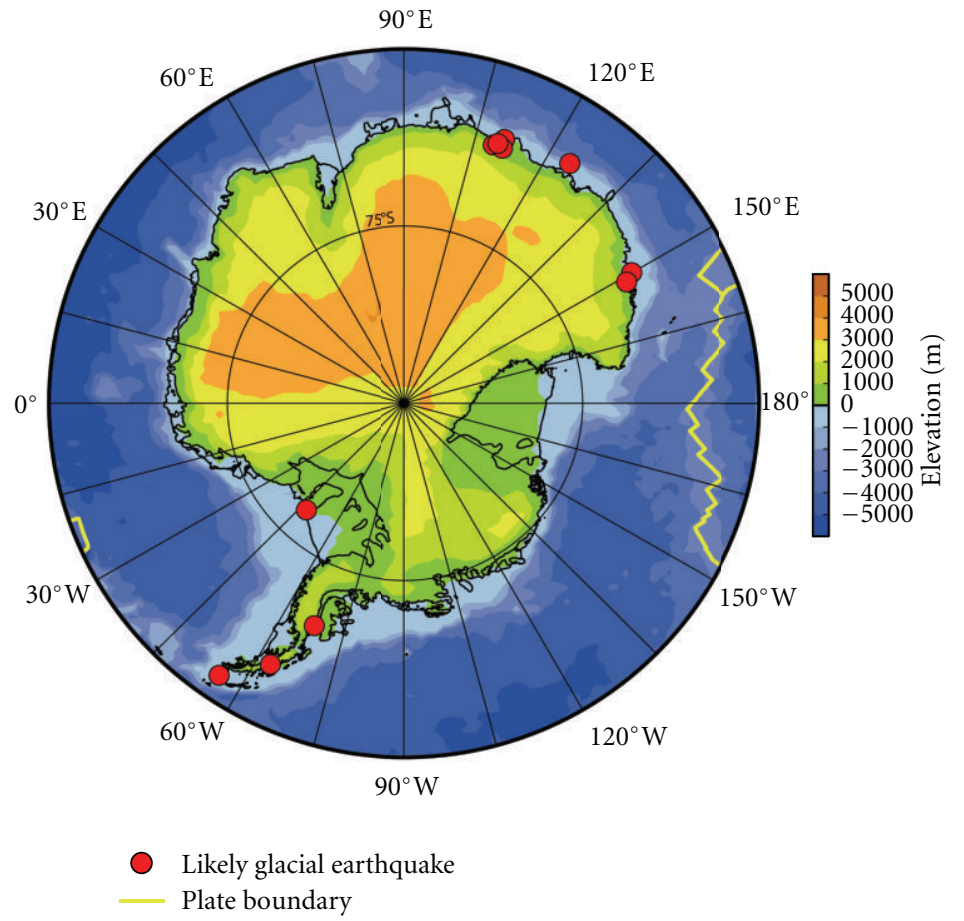

Figure 20: Hypocenters for the detected events that are likely to correspond to glacial earthquakes around Antarctica in 1993-2008 (after $[12])$.

MODIS images of the northeast Antarctic Peninsula

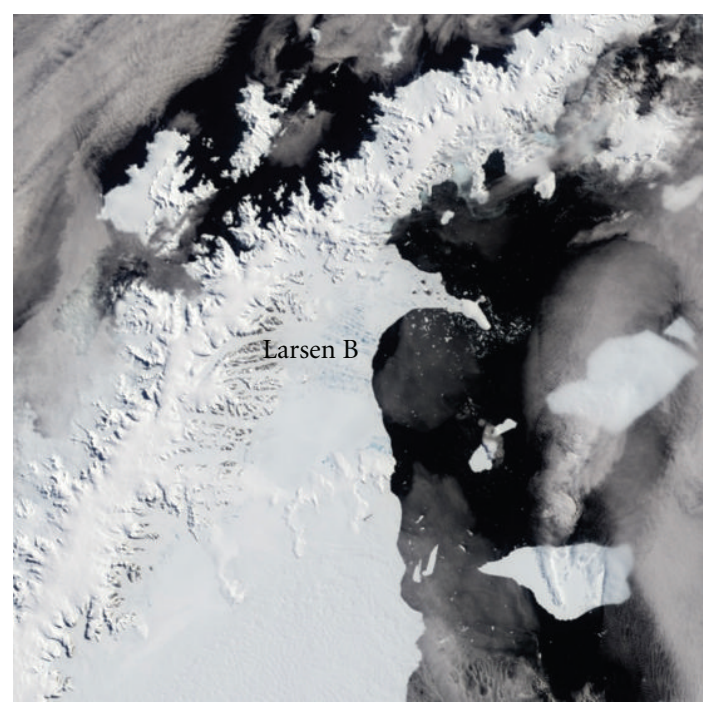

January 31,2002

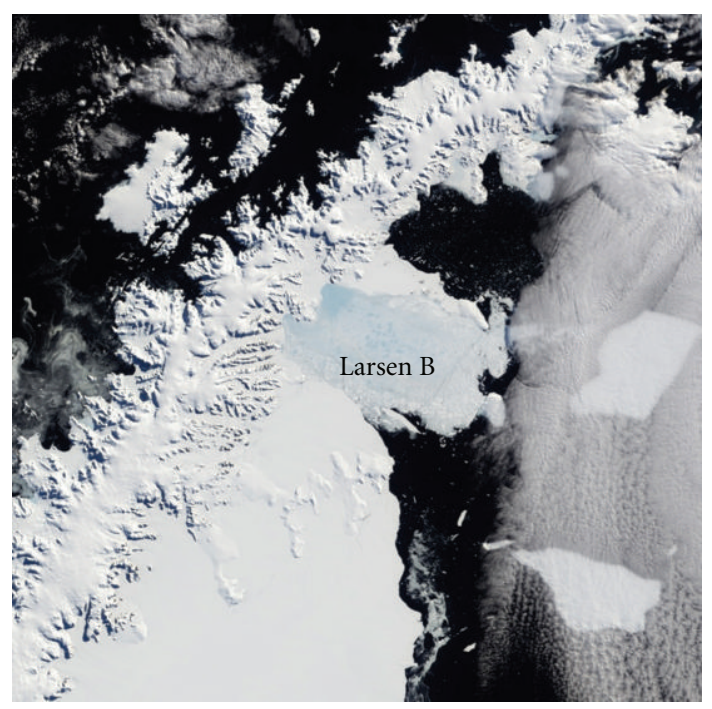

March 17, 2002

Figure 21: Moderate-resolution Imaging Spectroradiometer (MODIS) satellite imagery at the northern section of the Larsen B ice shelf on 31 January, 2002 (left), and on March 17, 2002 (right) respectively. A large floating ice mass on the eastern side of the Antarctic Peninsula has shattered and separated from the continent. The images are a courtesy of the National Snow and Ice Data Center (NSIDC), University of Colorado.

poorly located earthquakes, accordingly, could be a kind of large ice-quakes, because complicated subglacial topography with overlying ice-sheet in this area may efficiently cause icerelated seismic phenomena.
A complexity of the surface bedrock structure of Wilkes Land, moreover, might be influenced by tectonically weakened upper crust along with the present mobile belts, forced by the Tasmania microplate $[4,5]$. The aftershock area of the 
large Balleny Island Earthquake (1998 March, Mw = 8.1) in the Antarctic Oceanic Plate appears to continue with the continental area of Wilkes Land (Figure 18). Some ideas are supposed to generate the large earthquakes in this area, by assuming thermal stress of the young lithosphere, associated with unusual deformation due to Macquarie triple junction $[29,30]$.

From more detail, comparison with arrival times of the $\mathrm{X}$-phases recorded at FDSN stations, the maximum amplitudes of seismic phase appear to come to SYO with the delay of several seconds (Figure 12). On the basis, of several discussion above mentioned, the X-phases (event\#; eq015) could travel into the SEAL-2002 profile and then to the station SYO at a coast of the Lützow-Holm Bay. Hypocenters in the Antarctic Peninsula (Figure 17, (a)), otherwise in the relatively active intra-plate seismogenic region of Wilkes Land (Figure 17(b), could be the most plausible candidates to generate the X-phases on January 27, 2002.

Recently, a distribution of the events that are likely to correspond to glacial earthquakes is determined around Antarctica in 1993-2008 ([12]; Figure 20; Table 2). The origin times and epicenters are obtained by the surface-wave detection algorithm. Many of the hypocenters concentrate to locate at the coastal area of the Antarctic Peninsula, the Weddell Sea, and the Wilkes Land, particularly near Vincennes Bay. There are no exactly corresponding events for the X-phases (event\#; eq015) in their determined fourteen events, unfortunately, but the events on March 18 and March 30,2002 , in Table 2, show within the two months of time difference between the occurrences of X-phases on January 27. A similar analysis using surface waves by global dataset from 1997 to 2009 is conducted [31]; 17 glacier calving events are detected at the similar regions obtained by [12]. However, there are no corresponding events to the X-phases on January 2002 by our study.

It is also notified that the huge area of ice mass $\left(3,275 \mathrm{~km}^{2}\right)$ disintegrated from "Larsen B Ice Shelf," in the northeast Antarctic Peninsula, between January 31 and March 7 ([32, 33]; Figure 21) A large floating ice mass on the eastern side of the Antarctic Peninsula has shattered and separated from the continent. The break-off process of the floating ice mass could possibly generate the large energy to arrive at the X-phases on observation stations in SEAL-2002 profile, in Eastern Dronning Maud Land. The X-phases (event\#; eq015) on January 27, 2002 could presumably be the pre-cursor of the discharge events from the Larsen B Ice Shelf. There is a possibility that the other Xphases (event\#; eq006) on January 14 could also be another pre-cursor phases. It is a great pity that we do not record the SEAL exploration data until January 31,2002 , so as to detect directly the signals of the initiation process for breakoff at the Larsen B Ice Shelf. Regarding the floating ice shelves in Antarctica, moreover, calving mass loss occurred mostly by large tabular icebergs, which do not capsize and thus produce little low-frequency energy. Calving events of icebergs at the western Greenland are detected by recent available broadband seismic network [34]. The maximum energy at the $2-5 \mathrm{~Hz}$ band is very similar frequency range observed by the X-phases in this study of Antarctica.
TABle 2: Source parameters for 14 detected plausible glacial earthquakes in Antarctica during 1993-2008 (modified after 2010 [12]). Origin times and epicenters are determined by the surfacewave detection algorithm.

\begin{tabular}{lcccc}
\hline Date & Time & Latitude & Longitude & $M$ \\
\hline $1996 / 07 / 14$ & $19: 05: 52$ & -62.25 & -55.75 & $4.8^{\mathrm{C}}$ \\
$1998 / 05 / 11$ & $23: 17: 44$ & -67.00 & 109.00 & $4.9^{\mathrm{C}}$ \\
$1999 / 06 / 27$ & $15: 37: 52$ & -77.75 & -47.25 & $4.8^{\mathrm{C}}$ \\
$2000 / 04 / 09$ & $23: 25: 36$ & -66.25 & 110.75 & $4.9^{\mathrm{B}}$ \\
$2000 / 06 / 22$ & $23: 10: 48$ & -67.00 & 109.00 & $4.9^{\mathrm{C}}$ \\
$2001 / 11 / 24$ & $03: 20: 48$ & -67.00 & 109.00 & $4.9^{\mathrm{E}}$ \\
$2002 / 03 / 18$ & $08: 22: 40$ & -65.25 & -62.75 & $4.7^{\mathrm{C}}$ \\
$2002 / 03 / 30$ & $04: 15: 28$ & -67.00 & 109.00 & $4.8^{\mathrm{C}}$ \\
$2004 / 01 / 24$ & $08: 38: 24$ & -68.00 & 150.00 & $4.8^{\mathrm{C}}$ \\
$2004 / 01 / 31$ & $04: 31: 52$ & -67.00 & 111.00 & $4.9^{\mathrm{C}}$ \\
$2007 / 10 / 14$ & $02: 10: 08$ & -66.75 & 109.75 & $4.9^{\mathrm{B}}$ \\
$2008 / 05 / 18$ & $08: 35: 04$ & -65.50 & 124.50 & $4.8^{\mathrm{C}}$ \\
$2008 / 06 / 18$ & $00: 04: 00$ & -68.75 & 151.25 & $4.8^{\mathrm{B}}$ \\
$2008 / 07 / 21$ & $07: 34: 48$ & -69.75 & -67.75 & $4.8^{\mathrm{C}}$ \\
\hline
\end{tabular}

The letter code following the magnitude $M$ : indicates the quality of the detection and location: B: isthe highest quality and C/E: is the lowest.

Identification of the exact sources that produced these characteristic unknown signals has not yet been completed, and theoretical modeling will most likely be required to explain the physical processes. Many kinds of cryoseismic phenomena have been reported around the Ross Sea [35], the marginal sea of the Antarctic Peninsula [36,37], and the continental margin of Dronning Maud Land [38]. In particular, iceberg-originated harmonic tremor emanating from tabular icebergs is observed by both seismoacoustic and broadband seismics [35]. The tremor signals consisted of extended episodes of stick-slip ice-quakes generated when the ice-cliff edges of two tabular icebergs rubbed together during glancing, strike-slip iceberg collisions. Source mechanisms of the harmonic tremors might provide useful information for icedynamic behavior, and remotely monitoring of the activity.

Finally, a significant number of seismic events with smallto-middle magnitude could not actually be obtained by the global network particularly around Antarctica, since they have ambiguous arrivals in the waveforms and triggering algorism by the existing stations. The processes that result in seismic events associated with ice-sheet, sea-ice, iceshelf, and glaciers are all integral to the overall dynamics of cryosphere, and more condensed observations provide a means of monitoring changes in their behavior over time. Because seismology detects processes internal to the ice and the Earth, the monitoring capability that it provides is complementary to that of other methods, such as satellite remote sensing and GPS geodesy.

\section{Conclusions}

The characteristic seismic waveforms from various natural sources (teleseismic, local ice-quakes, and unknown Xphases) are obtained by the SEAL-2002 exploration in 
Eastern Dronning Maud Land, East Antarctica. Interesting features of the seismic wave propagation around Antarctica are significantly demonstrated. Anomalous behavior of the waves characterized by the focusing/defocusing effects is possibly caused by a valley structure beneath the stations located at the middle of the seismic profile. Several characteristics were identified by detailed spectra analyses. A difference of the response generated from the valley structure might exist for different kinds of incident waves that is, P-wave incidence on the valley results in a "frequency gap" while on the other hand, S-wave incidence produces both the "gap" and the "peak" with a sufficient delay of the arrival time. Although the origin of X-phases is not accurately identified, the most plausible candidates are an intraplate earthquake or a large ice-quake (glacial earthquake) in the Antarctic. Maybe the pre-cursor vibration of the break-off process at the Larsen $\mathrm{B}$ Ice Shelf could be the most plausible candidate to cause the $\mathrm{X}$-phases.

\section{Acknowledgments}

The authors would like to express thier appreciation to the participants of the Japanese Expedition members for their great efforts to carry out the SEAL seismic deployments on the ice sheet. Great thankfulness, especially, are to Professors H. Miyamachi, S. Toda, and T. Matsushima for their management of the experiments. The authors would like to express their sincere thankfulness to Professors Meredith Nettles of Lamont-Doherty Earth Observatory, Columbia University, Professors D. Blankenship and T. Diehl of the Institute for Geophysics, University of Texas at Austin, USA, and Professors I. Nakanishi of Kyoto University, for their critical reading and useful comments to improve the paper. The authors would like to express sincere thanks to Professors K. Shiraishi, Director-General of the National Institute of Polar Research, and Professors K. Kaminuma, K. Shibuya, Y. Motoyoshi, K. Doi, Y. Nogi, T. Hokada, and Y. Aoyama of NIPR for their useful discussions about geoscientific issues about Antarctica. The authors would like to express acknowledgement to the volume editor (Dr. M. S. Zhdanov) and two anonymous referees of the special issue on "Seismic Imaging 2012" of International Journal of Geophysics, for their sincere and useful comments. Parts of the figures have been prepared with generic mapping tools (GMT) [39].

\section{References}

[1] K. Kaminuma, "A revaluation of the seismicity in the Antarctic," Polar Geoscience, vol. 13, pp. 145-157, 2000.

[2] A. M. Reading, "Antarctic seismicity and neotectonics," in Antarctica at the Close of a Millennium, J. A. Gamble, D. N. B. Skinner, and S. Henrys, Eds., vol. 35, pp. 479-484, The Royal Society of New Zealand Bulletin, Wellington, New Zealand, 2002.

[3] A. M. Reading, "On seismic strain-release within the Antarctic Plate," in Antarctica: Contributions to Global Earth Sciences, D. K. Futterer, D. Damaske, G. Kleinschmidt et al., Eds., pp. 351356, Springer, Berlin, Germany, 2006.
[4] M. Kanao, Y. Nogi, and S. Tsuboi, "Spacial distribution and time variation in seismicity around the Antarctic Plate-Indian Ocean region," Polar Geosciences, no. 19, pp. 202-223, 2006.

[5] T. Himeno, M. Kanao, and Y. Ogata, "Statistical analysis of seismicity in a wide region around the $1998 \mathrm{Mw} 8.1$ Balleny Islands Earthquake in the Antarctic Plate," Polar Geosciences, vol. 5, pp. 421-431, 2011.

[6] S. Anandakrishnan and R. B. Alley, "Tidal forcing of basal seismicity of ice stream C, West Antarctica, observed far inland," Journal of Geophysical Research B, vol. 102, no. 7, pp. 15183-15196, 1997.

[7] M. Kanao and K. Kaminuma, "Seismic activity associated with surface environmental changes of the Earth system, around Syowa Station, East Antarctica," in Antarctica: Contributions to Global Earth Sciences, D. K. Futterer, D. Damaske, G. Kleinschmidt et al., Eds., pp. 361-368, Springer, Berlin, Germany, 2006.

[8] M. Kanao, A. Maggi, Y. Ishihara et al., "Interaction on seismic wves between Atmosphere-Ocean-Cryosphere and Geosphere in Polar Region," in Seismic Waves: Research and Analysis, M. Kanao, H. Takenaka, Y. Murai et al., Eds., InTech, Rijeka, Croatia, 2012.

[9] M. Kanao, M. Ishikawa, M. Yamashita, K. Kaminuma, and L. D. Brown, "Structure and evolution of the East Antarctic lithosphere: tectonic implications for the development and dispersal of Gondwana," Gondwana Research, vol. 7, no. 1, pp. 31-41, 2004

[10] M. Kanao, A. Fujiwara, H. Miyamachi et al., "Reflection imaging of the crust and the lithospheric mantle in the LützowHolm complex, Eastern Dronning Maud Land, Antarctica, derived from the SEAL transects," Tectonophysics, vol. 508, no. 1-4, pp. 73-84, 2011.

[11] H. Miyamachi, S. Toda, T. Matsushima et al., "Seismic refraction and wide-angle reflection exploration by JARE-43 on Mizuho Plateau, East Antarctica," Polar Geoscience, vol. 16, pp. 1-21, 2003.

[12] M. Nettles and G. Ekström, "Glacial earthquakes in greenland and antarctica," Annual Review of Earth and Planetary Sciences, vol. 38, pp. 467-491, 2010.

[13] M. Takada, S. Toda, D. Kamiya, T. Matsushima, and H. Miyamachi, "Radio echo sounding survey along the profile of the JARE-43 seismic exploration on the Mizuho Plateau, East Antarctica," Antarctic Record, vol. 47, no. 3, pp. 380-394, 2003.

[14] S. Mae, "The bedrock topography deduced from multiple radar echoes observed in the Mizuho Plateau, East Antarctica," Antarctica Recreation, vol. 61, pp. 23-31, 1978.

[15] A. P. Kapitsa, J. K. Ridley, G. D. Q. Robin, M. J. Siegert, and I. A. Zotikov, "A large deep freshwater lake beneath the ice of central East Antarctica," Nature, vol. 381, no. 6584, pp. 684686, 1996.

[16] M. J. Siegert, J. C. Ellis-Evans, M. Tranter et al., "Physical, chemical and biological processes in Lake Vostok and other Antarctic subglacial lakes," Nature, vol. 414, no. 6864, pp. 603609, 2001.

[17] M. Schimmel and H. Paulssen, "Noise reduction and detection of weak, coherent signals through phase-weighted stacks," Geophysical Journal International, vol. 130, no. 2, pp. 497-505, 1997.

[18] B. L. N. Kennett and E. R. Engdahl, "Traveltimes for global earthquake location and phase identification," Geophysical Journal International, vol. 105, no. 2, pp. 429-465, 1991.

[19] R. Tibi and D. A. Wiens, "Detailed structure and sharpness of upper mantle discontinuities in the Tonga subduction 
zone from regional broadband arrays," Journal of Geophysical Research B, vol. 110, no. 6, Article ID B06313, 14 pages, 2005.

[20] S. Kaneshima, T. Kubo, and S. Yoshioka, "Geophysical and mineralogical constraints on the post-spinel transformation for the Tonga slab," Physics of the Earth and Planetary Interiors, vol. 196-197, pp. 23-31, 2012.

[21] S. Kaneshima, "Seismic scatterers at the shallowest lower mantle beneath subducted slabs," Earth and Planetary Science Letters, vol. 286, no. 1-2, pp. 304-315, 2009.

[22] S.-X. Zang, Y.-Z. Zhou, J.-Y. Ning, and R. Q. Wei, "Multiple discontinuities near $660 \mathrm{~km}$ beneath Tonga area," Geophysical Research Letters, vol. 33, no. 20, Article ID L20312, 2006.

[23] A. Yamada, M. Kanao, and M. Yamashita, "Features of seismic waves recorded by seismic exploration in 2002: responses from valley structure of the bedrock beneath Mizuho Plateau," Polar Geoscience, vol. 17, pp. 139-155, 2004.

[24] D. A. Wiens, S. Anandakrishnan, J. P. Winberry, and M. A. King, "Simultaneous teleseismic and geodetic observations of the stick-slip motion of an Antarctic ice stream," Nature, vol. 453, no. 7196, pp. 770-774, 2008.

[25] R. A. Bindschadler, M. A. King, R. B. Alley, S. Anandakrishnan, and L. Padman, "Tidally controlled stick-slip discharge of a West Antarctic ice stream," Science, vol. 301, no. 5636, pp. 1087-1089, 2003.

[26] R. Butler and K. Anderson, "Global Seismographic Network (GSN)," IRIS Annual Report, 2008.

[27] P. J. Browne-Cooper, G. R. Small, and R. Whithworth, "Probable local seismicity at Wilkes Land, Antarctica," New Zealand Journal of Geology and Geophysics, vol. 10, pp. 443445, 1967.

[28] T. Wilson and R. Bell, "Earth structure and geodynamics at the Poles," in Understanding Earth'S Polar Challenges: International Polar Year 2007-2008, pp. 273-292, 2011.

[29] D. A. Wiens, M. E. Wysession, and L. Lawver, "Recent oceanic intra-plate earthquake in Balleny Sea was largest ever detected," EOS, Transactions American Geophysical Union, vol. 79, pp. 353-354, 1998.

[30] M. Nettles, T. C. Wallace, and S. L. Beck, "The March 25, 1998 Antarctic plate earthquake," Geophysical Research Letters, vol. 26, no. 14, pp. 2097-2100, 1999.

[31] X. Chen, P. M. Shearer, F. Walter, and H. A. Fricker, "Seventeen Antarctic seismic events detected by global surface waves and a possible link to calving events from satellite images," Journal of Geophysical Research B, vol. 116, no. 6, Article ID B06311, 2011.

[32] E. Rignot, G. Casassa, P. Gogineni, W. Krabill, A. Rivera, and R. Thomas, "Accelerated ice discharge from the Antarctic Peninsula following the collapse of Larsen B ice shelf," Geophysical Research Letters, vol. 31, no. 18, pp. L18401-4, 2004.

[33] T. A. Scambos, J. A. Bohlander, C. A. Shuman, and P. Skvarca, "Glacier acceleration and thinning after ice shelf collapse in the Larsen B embayment, Antarctica," Geophysical Research Letters, vol. 31, no. 18, pp. L18402-4, 2004.

[34] J. M. Amundson, J. F. Clinton, M. Fahnestock et al., "Observing calving-generated ocean waves with coastal broadband seismometers, Jakobshavn Isbrae, Grenland," Annals of Glaciology, vol. 53, no. 60, 2012.

[35] D. R. MacAyeal, E. A. Okal, R. C. Aster, and J. N. Bassis, "Seismic observations of glaciogenic ocean waves (microtsunamis) on icebergs and ice shelves," Journal of Glaciology, vol. 55, no. 190, pp. 193-206, 2009.
[36] D. R. Bohnenstiehl, R. P. Dziak, M. Parlk et al., "Seismicity of the polar seas: the potential for hydroacoustic monitoring of tectonic and volcanic processes," in Proceedings of the 12th Seoul International Symposium on Polar Sciences, pp. 11-14, Ansan, Republic of Korea, 2005.

[37] R. P. Dziak, M. Parlk, W. S. Lee et al., "Tectono-magmatic activity and ice dynamics in the Bransfield Strait back-arc basin, Antarctica," in Proceedings of the 16th International Symposium on Polar Sciences, pp. 59-68, Incheon, Republic of Korea, 2009.

[38] C. Müller and A. Eckstaller, "Local seismicity detected by the Neumayer seismological network, Dronning Maud Land, Antarctica: tectonic earthquakes and ice-related seismic phenomena," in Proceedings of the 9th International Symposium on Antarctic Earth Sciences Programme and Abstracts, vol. 236, 2003.

[39] P. Wessel and W. H. F. Smith, "New version of the generic mapping tools released," EOS, Transactions American Geophysical Union, vol. 76, p. 329, 1995. 

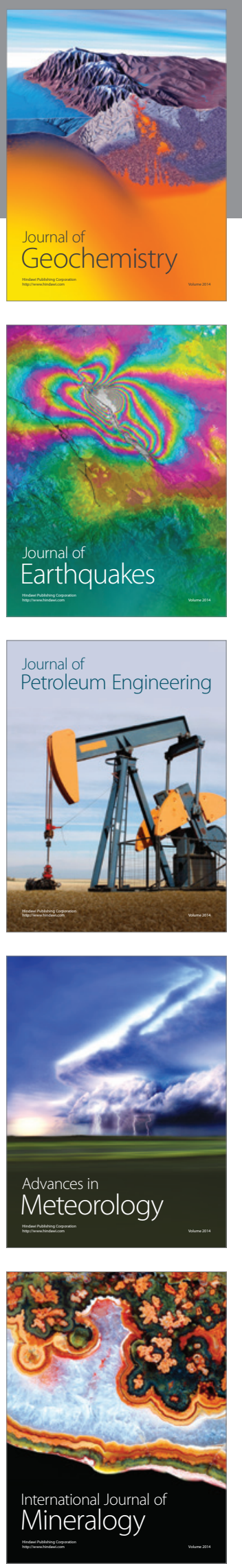
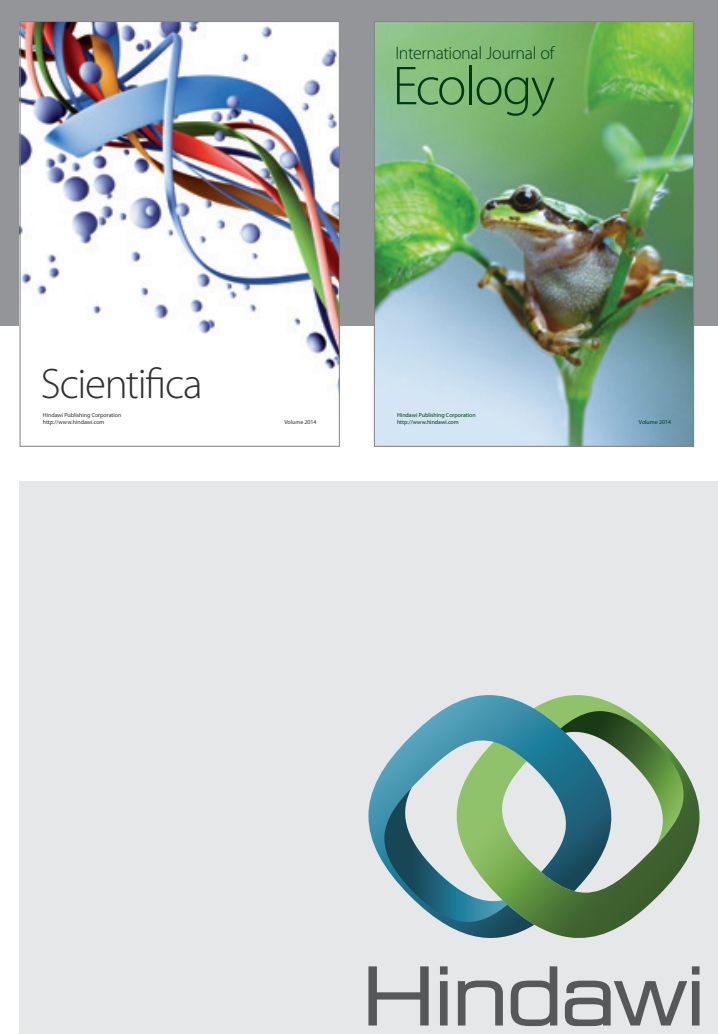

Submit your manuscripts at http://www.hindawi.com
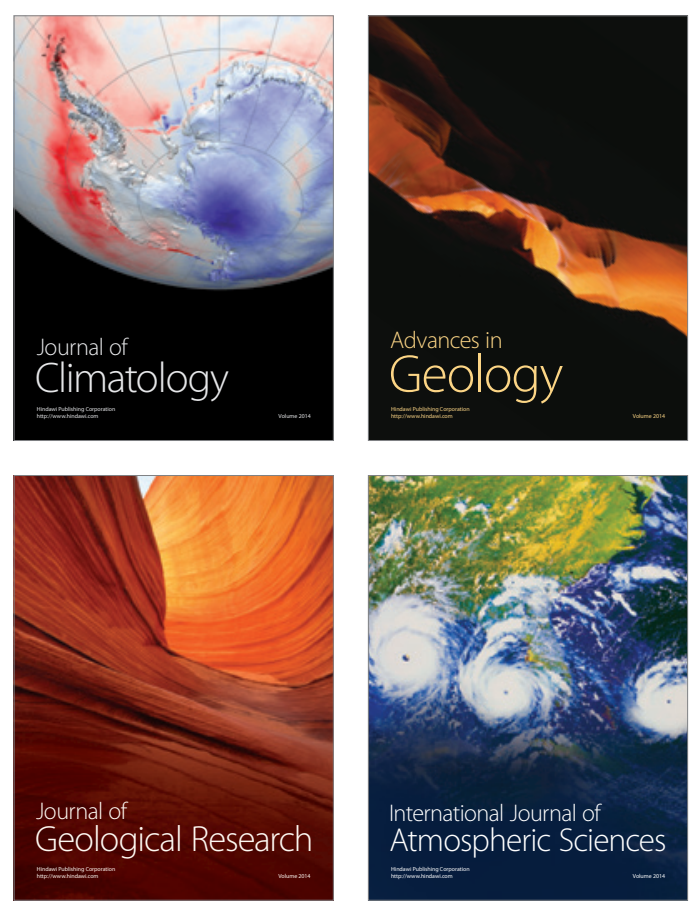
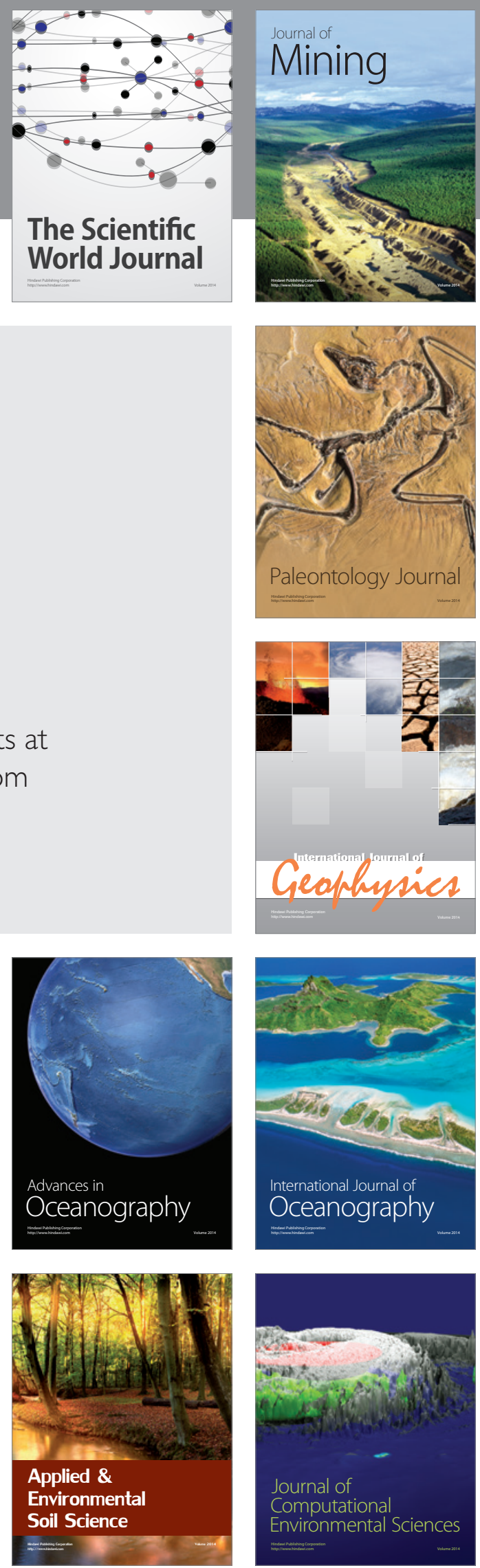